\title{
The Pathophysiological Role of Neutrophil Extracellular Traps in Inflammatory Diseases
}

\author{
Aldo Bonaventura ${ }^{1, *}$ Luca Liberale ${ }^{1,2, *}$ Federico Carbone ${ }^{1} \quad$ Alessandra Vecchié $^{1}$ \\ Candela Diaz-Cañestro ${ }^{2}$ Giovanni G. Camici ${ }^{2}$ Fabrizio Montecucco ${ }^{1,3,4}$ Franco Dallegri ${ }^{1,3}$
}

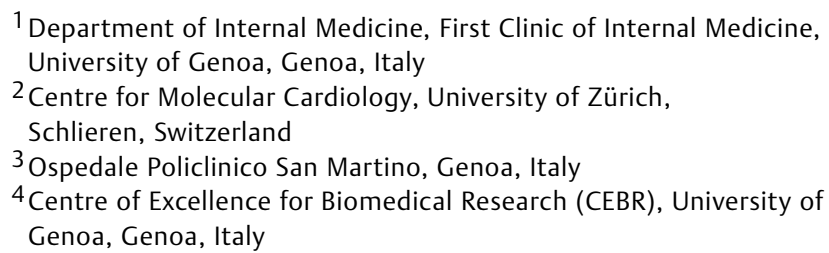

Address for correspondence Aldo Bonaventura, MD, Department of Internal Medicine, University of Genoa, 6 viale Benedetto XV, 16132 Genoa, Italy (e-mail: aldobon85@gmail.com).

Thromb Haemost 2018;118:6-27.

\begin{abstract}
Neutrophil pathogen-killing mechanism termed neutrophil extracellular traps (NETs) has been recently identified. NETs consist of chromatin and histones along with serine proteases and myeloperoxidase and are induced by a great variety of infectious and non-infectious stimuli. NETosis is a kind of programmed neutrophil death characterized by chromatin decondensation and release of nuclear granular contents, mainly driven by peptidylarginine deiminase 4 citrullination of histones. Although classically related to the protection against infectious pathogens, nowadays NETs have been described as a player of several pathophysiological processes. Neutrophil dysregulation has been demonstrated in the pathogenesis of most representative vascular diseases, such as acute coronary syndrome, stroke and venous thrombosis. Indeed, NETs have been identified within atherosclerotic lesions and arterial thrombi in both human beings and animal models. Moreover, an imbalance in this mechanism has been proposed as a critical source of modified and/or externalized autoantigens in autoimmune and

Keywords

- NETs

- infectious diseases

- autoimmune diseases

- metabolic disorders

- cancer inflammatory diseases. Finally, an update on the role of NETs in the pathogenesis of cancer has been included. In the present review, based on papers released on PubMed and MEDLINE up to July 2017, we point to update the knowledge on NETs, from their structure to their roles in infectious diseases as well as in cardiovascular diseases, autoimmunity, metabolic disorders and cancer, with a look to future perspectives and therapeutic opportunities.
\end{abstract}

\section{Introduction}

Neutrophil extracellular traps (NETs) have been recently recognized as a part of the wide defence strategy of neutrophils. In 2004, Brinkmann et al found that the induction of NETs by

These authors equally contributed to this work as first authors. interleukin (IL)-8 and lipopolysaccharide (LPS) supported their formation during inflammation and bacterial infection, as seen in the course of appendicitis. ${ }^{1}$ From this pivotal work, neutrophil alternative death pathway, named NETosis, ${ }^{2}$ has been indicated as a further way to act in innate immune defence even after their death. In recent years, NETs have been suggested to play a role also in non-infectious diseases, such as received

September 13, 2017

accepted after revision

October 22, 2017
Copyright (๐) 2018 Schattauer
DOI https://doi.org/ 10.1160/TH17-09-0630. ISSN 0340-6245. 
systemic lupus erythematosus (SLE), rheumatoid arthritis (RA), vasculitis, diabetes, atherosclerosis and cancer.

In the present review, based on papers released on PubMed and MEDLINE up to July 2017 (searched terms in combination: NETs, neutrophils, infections, autoimmunity, cancer, diabetes, cardiovascular [CV] diseases; articles have also been retrieved through searches of reference lists and authors' files), we aimed at updating knowledge on NETs, from their structure to their roles in infectious diseases as well as in CV disease, autoimmunity, metabolic disorders, and cancer, finally concentrating on future perspectives in terms of clinical usefulness for therapeutic purposes.

\section{Structure and Formation of NETs}

NETs are constituted by extracellular strands of unwound DNA usually in complex with histones and proteins from neutrophil primary, secondary and tertiary granules, including components with inflammatory and bactericidal activity, such as neutrophil elastase (NE), myeloperoxidase (MPO), cathepsin $\mathrm{G}$, lactoferrin, pentraxin 3, gelatinase, proteinase 3 and peptidoglycan-binding proteins. Generally, most of the neutrophil DNA is transcriptionally inactive and condensed into heterochromatin within the nucleus, with DNA wrapped around histones to form nucleosomes. Chromatin decondensation begins NETosis and is mediated by peptidyl arginase deaminase 4 (PAD4) catalyzing the conversion of histone arginines to citrullines, which weakens histone-DNA binding and consequently unwraps nucleosomes. A central role in
NET regulation is played by intracellular calcium as a second messenger of neutrophil activation, ${ }^{3}$ particularly PAD4 is activated by calcium itself. ${ }^{4} \mathrm{NE}$ is essential for NET production, too, as it cleaves histones during NET formation (-Fig. 1) ${ }^{5}$

Starting from in vitro studies, distinct activation pathways for NET formation have been identified and are believed to be active in vivo as well. These pathways include activation by integrins and toll-like receptors (TLRs) ${ }^{6,7}$ as signals triggering NETosis in response to bacterial infections. ${ }^{8}$ In this setting, Lselectin-mediated signals have also been described to elicit NETs in vitro. ${ }^{8}$ Most in vitro studies to identify mechanisms of formation of NETs used phorbol 12-myristate 13-acetate (PMA), despite this being an artificial trigger bypassing membrane receptors and their specific intracellular pathways. Actually, the widely described critical role of nicotinamide adenine dinucleotide phosphate oxidase (NOX) and MPO for NET formation may be linked to the in vitro activation by PMA. In chronic granulomatous disease (CGD) patients, a critical role of NOX in NET formation was confirmed in vivo. ${ }^{9}$

To date, three different models of NET formation have been identified. The best described one is called "suicidal NETosis" and lasts from 2 to 4 hours. ${ }^{10}$ After neutrophil activation, NOX increases its activity via the protein kinase $C$ (PKC)/rapidly accelerated fibrosarcoma (Raf)/mitogen-activated protein kinase ERK kinase (MERK)/extracellular signalregulated kinase (ERK) complex leading to cytosolic calcium intake, PAD4 activation and chromatin decondensation. Once the increase in cytosolic calcium takes place, PAD4 activation

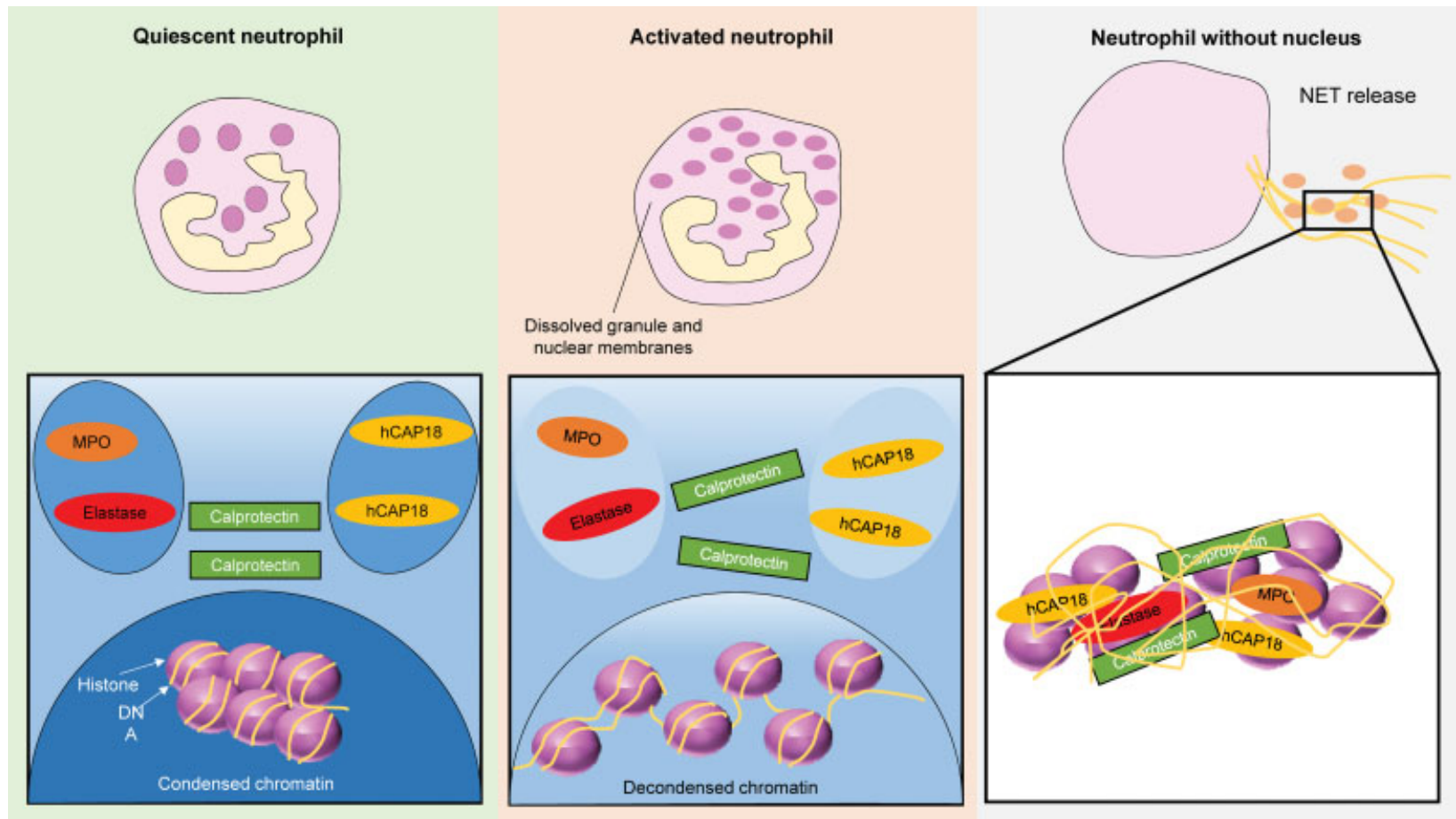

Fig. 1 Viable neutrophil extracellular trap (NET) formation. After neutrophil activation, peptidyl arginase deaminase 4 (PAD4) citrullinates some histone arginines to weaken the tight electrostatic binding between histones and DNA in nucleosomes. The immediate consequence is that both nuclear and granule membranes dissolved. At this moment, DNA is decondensed and meets citrullinated histones and granule proteins, which are all expelled from neutrophils as NETs ready to catch and even kill microbes. The last step sees the surface membrane coming intact leaving a viable neutrophil without nucleus. 
and chromatin decondensation occur. ${ }^{11}$ Then, ROS acts as second messengers by promoting the loss of the nuclear membrane. In this way, chromatin spreads throughout the cytoplasm mixing with cytoplasmic proteins and granule mediators and is finally released outside the cell through membrane pores and cellular lysis. Differently, during vital NET generation, neutrophils release NETs with no loss of nuclear or plasma membrane within 5 to 60 minutes independently of ROS and Raf/MERK/ERK pathway. This process evolves through different stages characterized by morphological changes: (1) nuclear envelope growth and vesicle release, (2) nuclear decondensation and (3) nuclear envelope disruption. ${ }^{12}$ Typically, this type of NET production is stimulated by the recognition of stimuli via TLRs and the C3 complement receptor ${ }^{6,13}$ as well as via the interaction between glycoprotein $\mathrm{Ib}$ in platelets with $\beta 2$ integrin in neutrophils by the activation of ERK. ${ }^{14}$ Finally, another type of vital, ROS-dependent NET generation has been described, in which mitochondrial DNA is released instead of nuclear DNA with NET formation within 15 minutes by the recognition of C5a or LPS. ${ }^{15}$

By definition, neutrophils are widely recognized as the only producers of NETs, although only a limited part of them (around 20\% depending on the stimulus) owns this skill contributing to the rising concept of neutrophils being a heterogeneous class of cells. ${ }^{16}$ Anyway, it is not known whether these phenotypic differences could be relevant to the ability of these neutrophils to undergo NETosis. Actually, the formation of extracellular traps (ETs) is far known to be restricted to cells of myeloid origin, even if the classical requirements for NET formation in PMA-stimulated neutrophils-such as respiratory burst, NE and MPO-are mainly met by neutrophils. However, eosinophils have also been described to generate a respiratory burst and their peroxidase can convert hydrogen peroxide into oxidizing halogen derivatives. ${ }^{17}$ These eosinophil ETs contain intact eosinophil granules, can catch bacteria and have been demonstrated in vivo in eosinophil-rich secretions. ${ }^{18,19}$ Basophils, too, can form ETs killing bacteria, but independently from NOX activity. ${ }^{20,21}$ On the contrary, mast cells were shown to release NOX-dependent ETs in vitro when stimulated by either Staphylococcus pyogenes or PMA. ${ }^{22}$ In mice, monocytes and macrophages can form ETs when stimulated by PMA. ${ }^{23}$

\section{NETs and Infections}

NETs have been demonstrated to own a broad effectiveness against different pathogens, such as bacteria, viruses, fungi, and parasites. Anyway, experimental data indicate that NETs trigger is restricted to specific microorganisms. To date, the precise role of NETs in sepsis has not been completely elucidated. NETs have been suggested to reduce bacterial spreading, especially in the early phase of infection, ${ }^{24}$ but their role appears to be limited: neither the lack of PAD4 nor the treatment with deoxyribonuclease (DNAse) impacted on bacterial load in animals subjected to sepsis. ${ }^{25,26}$ Furthermore, the excessive formation of NETs during sepsis is associated with organ damage. Interactions among platelets, neutrophils and activated endothelial cells lead to an increased formation of NETs, which interact with vascular endothelium ultimately leading to endothelial damage and organ injury in a histone- and MPO-dependent manner. ${ }^{27}$ Besides, histones can stimulate TLR2 and TLR4 to enhance the production of proinflammatory mediators via MyD88 signaling. ${ }^{28,29}$ Considering all these findings, it is clear that NETs might have a detrimental role in sepsis. Accordingly, both antibiotic therapy and anti-NETosis conditions, such as DNAse treatment or abrogation of PAD4, have been described to increase the survival rate of animals $\mathrm{s}^{26,30,31}$ and humans ${ }^{32}$ with sepsis by reducing NET burden. Microorganisms inducing NET production are indicated in - Table 1 .

\section{Bacteria}

A great number of Gram-positive and Gram-negative bacteria have been demonstrated to trigger NET formation. Brinkmann et al have used Staphylococcus aureus in 2004 in their seminal work as a stimulus to investigate NETosis. ${ }^{1}$ Some years later, Pilsczek et al deepened the previous finding by describing a faster, ROS-independent NET production in response to Staphylococcus-related infection, named vital NET release. ${ }^{10}$ S. aureus carries several virulence factors, among which leukotoxin GH and Panton-Valentine leukocidin can promote NET formation via an oxidative mechanism. ${ }^{33}$ Despite this, the bacterium has evolved different mechanisms to escape NET killing. For example, S. aureus can express pore-forming virulence factors neutralizing neutrophils by inducing necrosis at the expense of NETosis. ${ }^{34}$ Besides, its catalase expression blocks the stack of hydrogen peroxide, thus protecting the bacterium from intracellular oxidation and NETs. ${ }^{35}$ Furthermore, methicillin-resistant S. aureus (MRSA) has been found to express extracellular nucleases for biofilm dispersal and degradation of NETs. As a proof of this, mice infected by MRSA presented with a higher mortality with respect to controls infected with a nuclease-deficient strain that is more susceptible to extracellular killing by neutrophils. ${ }^{36}$

Streptococcus pneumoniae and $S$. pyogenes can induce NETosis, but they also developed some escape mechanisms. S. pyogenes virulence factor M1 modulates NET formation via an association with fibrinogen ultimately leading to a complex, which stimulates neutrophils. ${ }^{37}$ Furthermore, overexpression of M1 in susceptible strains of $S$. pyogenes confers resistance to extracellular killing because of the sequestration and neutralization of the LL37 (also known as cathelicidin), which is a neutrophil antimicrobial peptide significantly decreasing bacterial colonization. ${ }^{38}$ Mutant forms of M1 have been found with a decreased ability of NET induction and deletion of M1 increases the tendency toward NET killing. ${ }^{7}$ Similarly, $\alpha$-enolase from S. pneumoniae can increase neutrophil-migrating activity and induce their death by releasing NETs; however, genetic ablation of $\alpha$ enolase has not blocked NETosis. ${ }^{39}$ S. pneumoniae can escape NETs in a passive manner through its polysaccharide capsule reducing NET binding ${ }^{40}$ or trough active strategies. S. pneumoniae can express the DNase EndA, which facilitates the escape from NETs increasing the virulence in vivo. ${ }^{41}$ In a similar way, the nuclease Sda 1 in S. pyogenes degrades NETs 
Table 1 Microorganisms inducing NETosis

\begin{tabular}{|c|c|c|c|c|}
\hline Authors & Microorganism & $\begin{array}{l}\text { Microbe peptides } \\
\text { inducing NETs }\end{array}$ & Effects & Type of NETosis \\
\hline \multicolumn{5}{|l|}{ Bacteria } \\
\hline Pilsczek et al ${ }^{10}$ & S. aureus & $\begin{array}{l}\text { Leukotoxin GH; } \\
\text { Panton-Valentine } \\
\text { leukocidin }\end{array}$ & $\begin{array}{l}\text { ROS-independent induction } \\
\text { with nuclear DNA liberation, } \\
\text { TLR2- and C3-dependent }\end{array}$ & Vital \\
\hline Mori et $\mathrm{al}^{39}$ & S. pneumoniae & EndA; $\alpha$-enolase & ROS-independent induction & Suicidal \\
\hline $\begin{array}{l}\text { Carestia et al, }{ }^{14} \\
\text { Marin-Esteban et al, } \\
\text { Pieterse et al }{ }^{227}\end{array}$ & E. coli & Unknown & $\begin{array}{l}\text { Platelet-free or platelet-de- } \\
\text { pendent induction, TLR4-de- } \\
\text { pendent or independent, and } \\
\text { ROS-dependent or } \\
\text { independent }\end{array}$ & $\begin{array}{l}\text { Suicidal (in absence of } \\
\text { platelets) or vital (in presence } \\
\text { of platelets) }\end{array}$ \\
\hline Brinkmann et al ${ }^{1}$ & S. flexneri & IcsA and IpaB & Induction & Suicidal \\
\hline Brinkmann et al ${ }^{1}$ & S. typhimurium & Unknown & Induction & Suicidal \\
\hline $\begin{array}{l}\text { Möllerherm et al, }{ }^{49} \\
\text { Gillenius and Urban }\end{array}$ & Yersinia spp. & $\begin{array}{l}\text { Yops proteins and } \\
\text { invasion protein }\end{array}$ & $\begin{array}{l}\text { ROS-dependent induction, } \\
\text { PI3K signaling, } \beta \text {-integrin } \\
\text { pathway }\end{array}$ & Suicidal \\
\hline Braian et $\mathrm{al}^{51}$ & M. tuberculosis & $\begin{array}{l}\text { Adhesins, ESAT/6; } \\
\text { hsp72 is released } \\
\text { after } M \text {. tuberculosis } \\
\text { phagocytosis }\end{array}$ & $\begin{array}{l}\text { Phagocytosis-, elastase, and } \\
\text { ROS-dependent induction }\end{array}$ & Suicidal \\
\hline Seper et al ${ }^{17}$ & V. cholerae & Dns and $\mathrm{Xds}$ & ROS-dependent induction & Suicidal \\
\hline \multicolumn{5}{|l|}{ Viruses } \\
\hline Tripathi et al ${ }^{54}$ & Influenza virus & Unknown & $\begin{array}{l}\text { ROS- and PAD4-dependent } \\
\text { induction }\end{array}$ & Suicidal \\
\hline Moreno-Altamirano et $\mathrm{al}^{55}$ & Dengue virus & Unknown & $\begin{array}{l}\text { NET inhibition and Glut-1 } \\
\text { decreasing glucose capture }\end{array}$ & Unknown \\
\hline Saitoh et al $^{52}$ & HIV & Unknown & ROS-dependent induction & Suicidal \\
\hline Raftery et a ${ }^{57}$ & Hantavirus & $\begin{array}{l}\text { Viral particles, } \\
\text { Src kinase, and } \\
\beta 2 \text { integrin }\end{array}$ & ROS-dependent induction & Suicidal \\
\hline \multicolumn{5}{|l|}{ Fungi } \\
\hline Byrd et $\mathrm{al}^{229}$ & C. albicans & Unknown & $\begin{array}{l}\text { C3R- and fibronectin-depen- } \\
\text { dent and ROS-independent } \\
\text { induction }\end{array}$ & Vital \\
\hline Bruns et al ${ }^{60}$ & A. fumigatus & RodA & $\begin{array}{l}\text { ROS-dependent induction; } \\
\text { spores containing RodA do } \\
\text { not induce NETs }\end{array}$ & Suicidal \\
\hline Rocha et al ${ }^{61}$ & C. neoformans & Unknown & ROS and NETs inhibition & Unknown \\
\hline \multicolumn{5}{|l|}{ Parasites } \\
\hline Waisberg et a ${ }^{230}$ & P. falciparum & Agaphelin & $\begin{array}{l}\text { Induction through } P \text {. falciparum } \\
\text { and inhibition through } \\
\text { agaphelin }\end{array}$ & Suicidal \\
\hline Abi Abdallah et al ${ }^{65}$ & T. gondii & Unknown & $\begin{array}{l}\text { MEK-ERK-dependent } \\
\text { induction }\end{array}$ & Suicidal \\
\hline
\end{tabular}

Abbreviations: C3R, C3 receptor; ESAT, early secretory antigen target; HIV, human immunodeficiency virus; hsp, heat shock protein; MEK-ERK, mitogen-activated protein kinase/extracellular signal regulated kinase; NET, neutrophil extracellular trap; PAD, protein arginine deiminase; PI3K, phosphatidylinositol 3-kinase; ROS, reactive oxygen species; TLR, toll-like receptor.

and confers high virulence in vivo. ${ }^{42}$ Some strains of Streptococci can express the protease SpeB, which degrades Sda1 blocking the possibility to escape NETs, as found in mouse models. ${ }^{43}$ Interestingly, Sda1 has been demonstrated to degrade bacterial DNA, thus preventing the alert of the immune system via TLR9. ${ }^{44}$ This witnesses the virulence attributed to Sda1 which does not depend merely on NET escape, but probably on an intrinsic capacity.
NETs have been described to be significantly induced when neutrophils are stimulated with the serum of patients suffering from septic shock by Escherichia coli and this is likely to depend on TLR or complement receptor activation. ${ }^{45}$ The enteropathogenic strain WS2572 of E. coli can trigger NET formation in neutrophils from the bone marrow of wild-type mice. Interestingly, NET synthesis is abolished in neutrophils from glutathione reductase (GSR)-deficient mice suggesting a 
role for oxidative levels in the formation of NETs. ${ }^{46}$ As LL37 is associated with NET synthesis, it may play a relevant role in pathogen elimination by cooperating with NETs. ${ }^{47}$

Clostridium difficile is likely to stimulate NET formation, which may act to reach the injured areas of the intestinal epithelium and effectively hinder bacterial dissemination. ${ }^{48}$ Brinkmann et al demonstrated that Shigella flexneri is trapped by NETs in vitro and described the ability of DNA-associated elastase to abolish virulence factors IcsA and IpaB. ${ }^{1}$ Salmonella typhimurium has been shown to trigger NETs. S. typhimurium is usually trapped and eliminated by components of NETs, including granular proteins and H2A histone. ${ }^{1}$ In 2015, Möllerherm et al demonstrated that some serotypes of Yersinia enterocolitica could induce NETs in vitro within 1 hour of incubation, but induction diminished as the incubation time increased, maybe related to the effects of calcium- and magnesium-dependent nucleases. ${ }^{49}$ Vibrio cholerae can induce NETs in vitro after the contact with neutrophils. However, it is able to release the nucleases Dns and Xds as an evasion mechanism, thus feeding the infectious process. ${ }^{17}$ Finally, the facultative intracellular bacterium Mycobacterium tuberculosis has also been demonstrated to induce NETs when cocultured with neutrophils. Although NETs effectively trap and hinder the spread of M. tuberculosis, NET-derived components do not kill them. ${ }^{50}$ Braian et al proposed a role for the heat shock protein 72 sequestered in NETs in the interaction between neutrophils and macrophages during the early innate immune phase of an infection by M. tuberculosis. ${ }^{51}$

\section{Viruses}

Neutrophils are slightly involved in viral infections and only few studies investigated this issue. After neutrophils recognize human immunodeficiency virus (HIV)-1 nucleic acids through TLR7 and TLR8, they release ROS inducing NETs, which capture and neutralize HIV virions by MPO and $\alpha$ defensins. ${ }^{52}$ At the same time, HIV- 1 is also able to suppress NET formation being recognized by CD209 on dendritic cells (DCs) and leading them to the production of anti-inflammatory IL-10. ${ }^{52}$ Influenza A virus stimulates NETs via PAD4, while NET-associated $\alpha$-defensin- 1 blocks its replication by abrogating protein kinase $\mathrm{C}$ pathway. ${ }^{53}$ Also LL37 is involved in NET production in response to influenza $A$ virus in vitro, while arginine-rich $\mathrm{H} 3$ and $\mathrm{H} 4$ histones are important for viral aggregation and neutralization. ${ }^{54} \mathrm{~A}$ role for NETs has also been demonstrated for dengue virus ${ }^{55}$ and respiratory syncytial virus, although for the latter NETs can contribute to airway obstruction, thus exerting a dual protective and pathogenic role. ${ }^{56}$ NETs have also been detected in kidney biopsies and sera of patients infected by hantavirus. ${ }^{57} \mathrm{Han}-$ taan virus (HTNV), the prototype member of the genus Hantavirus, uses the $\beta 2$ integrin complement receptor (CR) 3 and CR4 as entry receptors, but can concurrently induce both ROS production and NET formation through the same $\beta 2$ integrin signaling. This systemic NET overflow is accompanied by the production of autoantibodies towards nuclear antigens. Moreover, HTNV has been found to stimulate human NETs in a more efficient way and at lower titres compared with vaccinia virus or LPS. ${ }^{57}$

\section{Fungi}

Neutrophils play a crucial role in the control of fungal infections, with NETs behaving as a precious weapon for this purpose. Candida albicans can change from yeast to hyphae; since hyphae are too big to be phagocytosed, extracellular killing by NETs is a perfect strategy to block this form as well as an efficient way to kill C. albicans as a single cell. ${ }^{58}$ Calprotectin has been identified as a major antifungal agent toward C. albicans and in fact is found to be associated with it in NETs; anyway, direct contact with the fungus is not required as calprotectin can chelate magnesium and zinc ions requested for Candida growth. ${ }^{59}$

Aspergillus fumigatus induces NET release in vitro requiring NOX..$^{35}$ Although NETs are fundamental for the elimination of A. fumigatus hyphae, they are not induced by spores because of the presence of RodA in the wall of spore cells. ${ }^{60}$ RodA-deficient A. fumigatus conidia induce NETs better than wild-type hyphae, so that RodA may have an inhibitory effect on NET formation by shielding yet unidentified NETinducing elements in conidia. As a further proof of it, $A$. fumigatus conidia are killed primarily by phagocytosis and not by NETs. ${ }^{60}$

Cryptococcus neoformans can modulate NET production. Particularly, neutrophils incubated with strains whose capsules contained glucuronoxylomannan and galactoxylomannan have been demonstrated to produce neither ROS nor NETs, but they did in non-capsulated strains. NET-associated antimicrobial peptide, such as MPO, elastase and collagenases, are needed to kill the fungus. ${ }^{61}$

\section{Parasites}

The number of studies investigating the role of NETs in immune responses toward protozoan parasites is increasing, although most of them have been conducted using animal-derived (e.g. goat or seal) neutrophils. Plasmodium falciparum induces NET formation. NETs entangle parasitized red blood cells and trophozoites together with antinuclear antibodies are involved in the pathophysiology of malaria in children and in the development of autoimmune phenotypes. ${ }^{62}$

The two main parasite stages of Leishmania, amastigotes and promastigotes, have been found to induce NETs ex vivo, which acts as a mechanism of defence against the infection. The induction of NETs is independent of NOS activity and ROS release. The entanglement of parasites within NETs decreased the viability of parasites, even if some authors state that the main role for NETs is immobilization of parasites and control of the infection. ${ }^{63,64}$

Toxoplasma gondii can stimulate NET formation. The presence of the parasite in the bloodstream is not necessary to trigger NET release. NETs kill around $25 \%$ of the entangled parasites, thus controlling the infection. In human bloodderived neutrophils, the production of NETs has been demonstrated by the activation of the Raf/MEK/ERK pathway in response to T. gondii. ${ }^{65}$

Finally, some animal parasites, such as Eimeria bovis and Besnoitia besnoiti, were reported to participate to NET formation. ${ }^{66-69}$ 


\section{NETs in Cardiovascular Diseases}

Dysregulation of neutrophil function has been recently indicated to play a pivotal role throughout the pathogenesis of most representative vascular diseases, such as acute coronary syndrome (ACS), stroke and venous thrombosis. Among these disorders, ACS and stroke are dramatic complications of advanced atherosclerosis. In the earliest phases of atherogenesis, neutrophils are recruited by upregulated adhesion molecules on the dysfunctional endothelial surface, where they exacerbate the oxidative stress and invade the vessel wall. After extravasation, and later in advanced atherosclerotic lesions, these cells sustain a vicious cycle leading to chronic inflammation and increased plaque vulnerability by releasing oxidative enzymes, ROS and chemokines. ${ }^{70}$ On the contrary, during venous thrombosis, neutrophils are largely recruited from activated endothelium through von Willebrand factor (vWF)-, tissue factor (TF)- and adhesion molecule-mediated pathways accounting for the large part of inflammatory cells found in thrombus during the early stage of the disease. ${ }^{71}$ Thus, after the description of NETosis in 2004, questions raised about its specific contribution to the pathogenesis of CV disease and, consequently, its feasibility as marker of disease or therapeutic target.

\section{NET Activity in CV Risk Factors and Early Endothelial Dysfunction}

Supporting the pathophysiological link between NETosis and vascular diseases, some known CV risk factors are associated with exacerbated or dysfunctional NET production. Diabetic patients showed high plasma levels of NET-associated proteins (e.g. elastase, mono-oligonucleosomes and doublestrand DNA $)^{72}$ and impaired NET release in response to bacterial infections. ${ }^{73}$ The constitutive NET formation described during hyperglycaemia can blunt their formation in response to proper stimuli. ${ }^{74}$ Interestingly, this phenomenon does not appear as a consequence of an impaired glycaemic control, rather it seems related to the chronic proinflammatory environment accompanying diabetes. ${ }^{75}$ Recently, age-related CV dysfunction has also been directly linked to NETosis in mice. While wild-type old mice showed a high rate of heart fibrosis and a decline in systolic and diastolic ventricular function, these features are considerably reduced in age-matched PAD4 ${ }^{-1-}$ animals, in which NETosis is abolished. ${ }^{76}$ Similarly, hypertension has been demonstrated to induce NETosis and platelet recruitment in wild type, but not in PAD4 ${ }^{-1-}$ or DNase-treated myocardium. ${ }^{76}$ On the contrary, endothelial dysfunction is widely described as primum movens of atherogenesis. NET-associated proteins have already shown their ability to induce endothelial toxicity and increase its thrombogenicity. Both circulating cell-free ds-DNA and histones are released by NETs upon the effect of inflammation and, acting as dangerassociated molecular patterns (DAMPs), they can exacerbate inflammation itself, thus creating a deleterious vicious cycle at the endothelial level. ${ }^{77,78}$ In particular, histones have been shown to stimulate the exocytosis of proinflammatory and procoagulant Weibel-Palade bodies by endothelial cells. ${ }^{79}$
Moreover, matrix metalloproteinase (MMP)-9 contained within the NET web can reduce aortic endothelium-dependent vasorelaxation and trigger endothelial dysfunction through the activation of MMP-2. ${ }^{80}$ Interestingly, interactions between NET and dysfunctional endothelium are not unidirectional: activated endothelial cells are able to induce NET formation in a C-X-C motif chemokine (CXCL)8-dependent way and extensive neutrophil co-culture with endothelial cells results in endothelial damage, which could be abrogated by DNase or through the inhibition of NOX. ${ }^{81}$

\section{The Role of NETs in Atherosclerosis and Atherothrombosis}

NETs have been identified within atherosclerotic lesions and arterial thrombi in both human samples and atherosclerotic animals. ${ }^{82,83}$ The pathophysiological relevance of NETosis in atherosclerosis has been underscored by inhibiting PAD4 in ApoE ${ }^{-1-}$ mice with chloramidine. ${ }^{84}$ In particular, chloramidinetreated mice showed reduced vessel inflammation (e.g. interferon [IFN]- $\alpha$ levels), plaque size and thrombotic attitude. ${ }^{84}$ Recently, interesting insights in this field came from a research by Warnatsch et al. ${ }^{85}$ In this study, cholesterol crystals were able to induce NETosis in vivo and NETs could prime macrophage to produce pro-IL-1 $\beta$, thus activating a strong pro-inflammatory Th17 response. ${ }^{85}$ In atherosclerotic-prone mice fed with high cholesterol diet, intraplaque NETs co-localized with cholesterol crystals and macrophages near the necrotic core, while they did not in more stable zones. The same atherosclerosis model, when lacking NE and proteinase-3, developed dramatically smaller and less inflamed atherosclerotic lesions with respect to $\mathrm{ApoE}^{-1-}$ control mice, together with lower plasma IL-1 $\beta$ levels. ${ }^{85}$ Another mechanism by which NETs are supposed to increase atherogenesis has been described by Döring et al and involves plasmacytoid DC. ${ }^{86}$ In this paper, complexes formed by extracellular DNA and neutrophil-derived proteins have been shown to increase the plaque burden by stimulating a DC-driven strong type I IFN response. On the contrary, the absence of these cells leads to decreased atherogenesis and reduced inflammatory response. ${ }^{86}$

Preclinical studies specifically investigating the effect of NET modulation on atherothrombosis are scarce and the current knowledge largely derives from immunohistochemical analysis of human specimens. The blockage of neutrophil-derived nucleosomes by anti-histones antibodies treatment has been demonstrated to prolong the time to occlusion in the ferric chloride arterial injury model. ${ }^{87}$ This effect was completely reversed in elastase/cathepsin $\mathrm{G}$ double knockout mice; under a mechanistic point of view, nucleosomes are able to facilitate thrombosis by allowing NE to digest the TF pathway inhibitor. ${ }^{87}$ Moreover, neutrophil-derived serine proteases and nucleosomes, two main components of NETs, may contribute to arterial thrombosis in the context of sterile inflammation supporting dramatic atherosclerosis complications, such as myocardial infarction and ischemic stroke. In a mouse model of myocardial ischaemia/reperfusion (I/R) injury, NETosis targeting via DNase I injection has shown cardioprotective features by reducing both plasma levels of nucleosomes and citrullinated histone 3 (citH3) presence at the site of injury. ${ }^{88}$ 
Similar features have been found after cardiac ischemic damage in PAD4 ${ }^{-1-}$ mice. ${ }^{88}$ Finally, concurrent DNase I and recombinant-tissue plasminogen activator (r-TPA) therapy has been demonstrated to reduce infarct size, no-reflow area and postischaemic left ventricle remodelling in an animal myocardial I/ $\mathrm{R}$ injury model, whereas these beneficial effects have not been observed in rats treated with DNase and r-TPA alone, ${ }^{89}$ thus suggesting a potential role for anti-NET agents as therapeutic strategy during ischaemic heart diseases.

In human coronary specimens from infarcted patients, NETs were most frequently found in the early stages of thrombus evolution (e.g. fresh and lytic thrombi), while these cells missed in advanced, organized thrombi. ${ }^{83}$ Recently, a study analysing coronary thrombectomy from patients with ST-elevated myocardial infarction showed that the thrombus NET burden correlates in a positive fashion with the infarct size and negatively with ST-segment resolution..$^{90}$ In the same work, the plasma collected from the culprit lesion site contained higher concentrations of NETrelated biomarkers when compared with femoral samples from the same patients as well as DNase activity at the culprit lesion site negatively correlated with thrombus NET burden and infarct size. Moreover, recombinant DNase accelerated the coronary thrombi lysis in vitro. ${ }^{90}$ In particular, Stakos et al recently demonstrated that neutrophils at culprit lesion site can release thrombogenic signals through NET formation and subsequent delivery of active TF. ${ }^{91}$

Even if most of the currently available evidence links NETs to atherothrombosis, they may also participate to earlier superficial erosion of the plaque by inducing endothelial cell apoptosis. ${ }^{92}$ Of importance, biomarkers of NETosis already showed to be positively associated with the severity of atherosclerosis and to predict future CV events (-Table 2). Under this point of view, Borissoff et al gave fundamental insights by correlating the disease severity in patients with coronary disease assessed by computed tomographic angiography and markers of NETosis. ${ }^{93}$ Although these data underline the importance of such death mechanism in atherosclerosis-related diseases, more studies are needed to overcome the low specificity of some NET-related biomarkers (e.g. histones and double strain [ds]DNA).

NETs have also been investigated in the setting of acute ischemic stroke (AIS) highlighting the role of thromboinflammation as a pivotal player in the pathophysiology of ischaemic stroke ${ }^{94}$ along with thrombosis and inflammation, which constitute a loop of bidirectional regulation contributing to ischaemic damage in brain or other tissues. ${ }^{95}$ Recently, Vallés et al described for the first time that three markers of NETs-dsDNA, nucleosomes and citH3-are significantly elevated in patients with AIS when compared with healthy subjects; in particular, the greatest proportional increase was found for the most specific NET marker citH3. ${ }^{96}$ Levels of the above-mentioned NET markers have been correlated with stroke severity at onset and discharge by the clinical National Institutes of Health Stroke Scale and modified Rankins scale scores as well as by significant elevations of citH3, dsDNA and nucleosomes. Authors also found that citH3 and dsDNA levels were higher in patients with cardioembolic stroke, this being related to a higher inflammatory activation. This issue was in touch with the significant increase in NET markers for patients with a history of atrial fibrillation (AF), too. Finally, citH3 has been found elevated especially in older patients, with higher fasting glucose, and with prior AF and independently associated with all-cause mortality at 1 -year follow-up. ${ }^{96}$ These results indicate that citH3 might represent a useful prognostic marker in patients with AIS, warranting new researches for neuroprotective therapies in this field. The results of other studies investigating NETs in AIS are listed in -Table 3.

\section{NETs and Venous Thrombosis}

Although arterial and venous thromboses are different syndromes with different main causes, they found in NETs a common pathogenic pathway. Several key components of NETs, such as nucleic acids, histones and enzymes, have shown venous procoagulant features. ${ }^{97-99}$ Histone infusion leads to vWF release and has been found to accelerate the thrombus formation in inferior vena cava (IVC) stenosis model of deep venous thrombosis (DVT). ${ }^{100}$ Thrombi from the same animal models are characterized by an important presence of NETs associated with vWF, especially in the earliest stages. ${ }^{100,101}$ NETs interact with vWF through histone A1 domain, ${ }^{102}$ but they can also bind other thrombosis-related proteins (e.g. fibronectin) containing several DNA-binding domains. ${ }^{101}$ Not only vWF but also TF sustains the strong relation between venous thrombosis and NETs. During the generation of NET, neutrophils produce both TF and NE. NE is critical to further increase TF activity by the cleavage of TF inhibitory molecules. $^{71,91}$ Thus, after platelet and neutrophil activation by procoagulant factors, the latter generates NETs acting as trap and framework for thrombus elements, such as red blood cells, leukocytes, platelets and activated coagulation factors. ${ }^{71,103}$ The crucial contribution of NETosis in venous thrombosis has been underlined by PAD4 ${ }^{-1-}$ mice, in which the lack of NETs results in fewer thrombi after IVC stenosis compared with wild-type ones; similar effects have also been demonstrated by the administration of DNase I. ${ }^{104}$ Although some controversies still remain, ${ }^{105}$ these results encouraged scientists to shift their attention from preclinical setting to the bedside. In 2013, two papers showed an association between increased plasma markers of NETs and DVT (- Table 2). The first article stated that in patients with DVT circulating nucleosomes and elastase- $\alpha 1$-antitrypsin complexes, levels are increased with respect to patients with first clinical suspicion of DVT, which has been then excluded by ultrasonography. ${ }^{106}$ The second study focused on plasma DNA level showing higher concentrations of this marker in DVT patients and its correlation with D-dimer, Wells score and MPO, the third indicating neutrophil as the source of the nucleic acid. ${ }^{107}$ Recently, the immunohistochemical analysis of thrombi at different stages of development from human surgery or autopsy showed high presence of NETs (indicated by the association of citrullinated histone $\mathrm{H} 3$ with MPO and DNA) in thrombi during the phase of organization. ${ }^{108}$ 
Table 2 Recent studies investigating NET biomarkers in CV diseases

\begin{tabular}{|c|c|c|c|c|}
\hline Author & Year & Patients & Biomarkers & Results \\
\hline \multicolumn{5}{|l|}{ Atherothrombosis } \\
\hline Shimony et $\mathrm{al}^{231}$ & 2010 & $\begin{array}{l}16 \text { patients with STEMI and } \\
47 \text { healthy subjects }\end{array}$ & dsDNA & $\begin{array}{l}\text { dsDNA levels were significantly } \\
\text { higher in patients compared with } \\
\text { controls }(p=0.001) \text { and positively } \\
\text { correlated with levels of CK and TnT } \\
(r=0.79 \text { and } 0.65, p<0.001 \text { and } \\
p=0.006 \text {, respectively) }\end{array}$ \\
\hline Borissoff et al ${ }^{93}$ & 2013 & $\begin{array}{l}282 \text { patients with suspected } \\
\text { coronary heart disease } \\
\text { undergoing coronary CTA } \\
\text { were grouped according to } \\
\text { the presence and severity of } \\
\text { CAD }\end{array}$ & $\begin{array}{l}\text { dsDNA, } \\
\text { nucleosomes, } \\
\text { citH4 and MPO-DNA } \\
\text { complexes }\end{array}$ & $\begin{array}{l}\text { dsDNA, nucleosomes and MPO-DNA } \\
\text { complex levels were significantly } \\
\text { higher in patients with severe CAD } \\
(p=0.003, p<0.001 \text { and } p<0.05 \text {, } \\
\text { respectively) or abundant coronary } \\
\text { artery calcification ( } p<0.001 \text { for all) } \\
\text { with respect to healthy controls. } \\
\text { Their levels correlate with the } \\
\text { severity of luminal stenosis } \\
\text { ( } p \leq 0.001 \text { for all) and with number } \\
\text { of diseased coronary artery segments } \\
\text { ( } p \leq 0.001 \text { for all). } \\
\text { Baseline values higher than the total } \\
\text { group median of dsDNA (OR, } 3.12 ; \\
95 \% \text { CI, } 1.27-7.63 ; p=0.013) \text {, } \\
\text { nucleosomes (OR, } 2.59 ; 95 \% \text { Cl, } \\
1.09-6.14 ; p=0.030) \text { and } \\
\text { MPO-DNA (OR, 3.53; } 95 \% \mathrm{Cl} \text {, } \\
1.38-9.03 ; p=0.009 \text { ) were signifi- } \\
\text { cantly associated with the occurrence } \\
\text { of MACEs }\end{array}$ \\
\hline Cui et al ${ }^{232}$ & 2013 & $\begin{array}{l}137 \text { ACS patients ( } 51 \text { with } \\
\text { unstable AP, } 37 \text { with NSTEMI, } \\
\text { and } 49 \text { with STEMI), } 13 \text { stable } \\
\text { AP patients, and } 60 \text { healthy } \\
\text { controls }\end{array}$ & dsDNA & $\begin{array}{l}\text { ACS patients showed higher dsDNA } \\
\text { levels compared with stable AP } \\
\text { patients and control group }(p<0.05 \\
\text { for both). Significant differences in } \\
\text { dsDNA concentrations were } \\
\text { observed in ACS group among } \\
\text { unstable AP, NSTEMI, and STEMI } \\
\text { sub-groups ( } p<0.05 \text { for all). } \\
\text { dsDNA levels were different among } \\
\text { ACS patients divided into three } \\
\text { groups according to Gensini score } \\
\text { with increasing levels of dsDNA } \\
\text { concurrent with increasing Gensini } \\
\text { score ( } p<0.05 \text {, for all) }\end{array}$ \\
\hline Mangold et al ${ }^{90}$ & 2015 & $\begin{array}{l}111 \text { patients with STEMI } \\
\text { undergoing } \mathrm{PCl}\end{array}$ & $\begin{array}{l}\text { Nucleosomes and } \\
\text { dsDNA }\end{array}$ & $\begin{array}{l}\text { Nucleosomes and dsDNA levels were } \\
\text { significantly higher at the culprit } \\
\text { lesion site than to the femoral artery } \\
(p=0.0002 \text { and } p<0.0001 \\
\text { respectively) }\end{array}$ \\
\hline Helseth et $\mathrm{al}^{233}$ & 2016 & $\begin{array}{l}30 \text { patients with CAD under- } \\
\text { going } \mathrm{PCI}(20 \text { with STEMI and } \\
10 \text { with stable } A P)\end{array}$ & $\begin{array}{l}\text { dsDNA and } \\
\text { nucleosomes }\end{array}$ & $\begin{array}{l}\text { dsDNA and nucleosome levels were } \\
\text { higher in patients with STEMI } \\
\text { compared with patients with AP } \\
(p<0.03 \text { for both). dsDNA signifi- } \\
\text { cantly correlated with peak TnT and } \\
\text { CK-MB at day } 5 \text { ( } p=0.03 \text { ) and with } \\
\text { lesion size assessed by MRI at days } 5 \\
\text { and } 7 \text { ( } p=0.01 \text { and } 0.04 \text {, } \\
\text { respectively). Nucleosomes correlate } \\
\text { with infarct size at day } 5(p=0.02)\end{array}$ \\
\hline
\end{tabular}


Table 2 (Continued)

\begin{tabular}{|c|c|c|c|c|}
\hline Author & Year & Patients & Biomarkers & Results \\
\hline \multicolumn{5}{|c|}{ Venous thrombosis } \\
\hline $\begin{array}{l}\text { van Montfoort } \\
\text { et al }\end{array}$ & 2013 & $\begin{array}{l}150 \text { patients with sympto- } \\
\text { matic DVT and } 195 \text { patients } \\
\text { with clinical suspicion of DVT } \\
\text { in whom the pathology was } \\
\text { excluded by US examination }\end{array}$ & Nucleosomes & $\begin{array}{l}\text { Nucleosome levels were significantly } \\
\text { higher in patients with DVT } \\
(p<0.001) \text { and positively correlated } \\
\text { with neutrophil activation in both } \\
\text { case and control samples ( } p<0.001 \\
\text { for both). An increase in nucleosome } \\
\text { levels }>80 \text { th percentile carried an } \\
\text { increased risk of DVT than levels } \\
\leq 80 \text { th percentile after adjustment } \\
\text { for potential confounders } \\
\text { (OR: } 3.0,95 \% \mathrm{Cl}: 1.7-5.0)\end{array}$ \\
\hline Diaz et al ${ }^{107}$ & 2013 & $\begin{array}{l}47 \text { patients with sympto- } \\
\text { matic DVT, } 28 \text { patients with } \\
\text { clinical suspicion of DVT not } \\
\text { confirmed by US examina- } \\
\text { tion, and } 19 \text { healthy } \\
\text { volunteers }\end{array}$ & dsDNA & $\begin{array}{l}\text { dsDNA levels were higher in DVT } \\
\text { group with respect to both negative } \\
\text { control groups }(p<0.01 \text { for both). } \\
\text { dsDNA levels showed a positive } \\
\text { correlation with CRP ( } p<0.01) \text {, } \\
\text { D-dimer }(p<0.01) \text {, and vWF } \\
(p<0.01) \text { and the Wells score } \\
(p<0.01) \text {. A negative correlation } \\
\text { was found with ADAMST13 } \\
(p<0.01)\end{array}$ \\
\hline
\end{tabular}

Abbreviations: ADAMST13, a disintegrin and metalloproteinase with thromboSpondin-1 motifs (13th member of the family); CAD, coronary artery disease; citH4, citrullinated histone H4; CK-MB, creatine kinase, muscle and brain; CRP, C-reactive protein; CTA, computed tomography angiography; $\mathrm{CV}$, cardiovascular; ds, double strain; DVT, deep venous thrombosis; HR, hazard ratio; LV, left ventricle; MACEs, major cardiovascular events; MI, myocardial infarction; MPO, myeloperoxidase; MRI, magnetic resonance imaging; NSTEMI, non-ST-elevated myocardial infarction; N/L, neutrophil to lymphocyte; OR, odds ratio; PCI, percutaneous coronary intervention; RR, relative risk; SINTAX, Synergy between Percutaneous Coronary Intervention with Taxus and Cardiac Surgery; STEMI, ST-elevated myocardial infarction; TnT, troponin T; US, ultrasound; vWF, von Willebrand factor.

\section{NETs in Autoimmune and Autoinflammatory Diseases}

Systemic autoimmune diseases develop as multistep processes through a complex interplay between genetic and environmental factors leading to cellular damage and the consequent exposure of immune cells to autoantigens. The imbalance of different cell death mechanisms (apoptosis, necroptosis, pyroptosis, NETosis and autophagy) has been proposed as a critical source of modified and/or externalized autoantigens. ${ }^{109}$ Especially nuclear material released from NETs seems to be more immunogenic than the apoptotic one. Both native and oxidized self-DNA bound to NETs activate DCs to synthetize IFN- $\alpha$ in a TLR-dependent manner. ${ }^{110,111}$ In mice, the immunization with NET-loaded DCs promotes the development of autoimmunity better than apoptotic neutrophil debris. ${ }^{112}$ NETs also increase T-cell response to antigens and activate B cells to induce immunoglobulin (Ig) class switching and antibody production. ${ }^{113}$ Once externalized, oxidized DNA is also more resistant to degradation and this behaviour contributes to sustain a dysregulated immune response. ${ }^{114}$ In addition, NET-mediated activation of the inflammasome further amplifies the inflammatory response through a feed-forward loop. The inflammasome stimulation triggers synthesis and release of IL-18 and IL-1 $\beta$, which in turn induces NET formation. ${ }^{115}$ Activation of classic and alternative pathways of complement system as well as coagulation cascade is additional immunogenic mechanisms linking NETs to autoimmune/autoinflammatory diseases. ${ }^{116}$ Noteworthy, many of the proteins found in NETs are recognized as major autoantigenic targets in rheumatologic diseases: dsDNA and histones in SLE, vimentin and enolase in RA, MPO and proteinase- 3 in vasculitis associated with antineutrophil cytoplasmic antibodies (ANCAs). Different autoantibody profiles may then be influenced by the cargo protein within NETs and detailed analysis revealed differences in protein content and posttranslational modifications associated with different autoimmune diseases. ${ }^{117-119}$

\section{Systemic Lupus Erythematosus}

Neutrophils from patients with SLE showed various abnormalities in their phenotype and function. ${ }^{120}$ Circulating levels of apoptotic neutrophils, which may provide excess autoantigen such as dsDNA, are increased in patients with SLE and correlate with disease activity. ${ }^{121}$ Furthermore, patients with SLE are characterized by a distinct neutrophil subpopulation known as low-density granulocytes (LDGs). ${ }^{122}$ Those cells are prone to release proinflammatory cytokines and show enhanced NET formation. NETs released by LDGs contain high levels of autoantigens and immunostimulatory molecules, such as LL37, MMP-9, and $\alpha$ - and $\beta$-defensins. ${ }^{123}$ LDGs are also enriched of dsDNA and oxidized nucleic acids, which are strong inducers of IFN- $\alpha$ and NOD-like receptor family pyrin domain-containing (NLRP)3 inflammasome. ${ }^{115,124}$ Finally, patients with SLE exhibit impaired NET clearance correlating with disease activity. ${ }^{125}$ As a result of overproduction and defective clearance of NETs, 
Table 3 Studies investigating NET biomarkers in acute ischemic stroke

\begin{tabular}{|c|c|c|c|c|}
\hline Author & Year & Patients & Biomarkers & Results \\
\hline Rainer et $\mathrm{al}^{234}$ & 2003 & $\begin{array}{l}88 \text { patients with stroke-like } \\
\text { symptoms presenting to the } \\
\text { ED }\end{array}$ & nDNA & $\begin{array}{l}\text { nDNA concentrations within } 3 \text { h of symp- } \\
\text { tom onset were higher in died patients } \\
\text { than in those who survived at discharge } \\
(p=0.03) \text { as well as in died patients with } \\
\mathrm{NIHSS} \text { scores }>8 \text { who survived to } 6 \text { mo } \\
(p=0.002) \text {. nDNA concentrations corre- } \\
\text { lated with the volume of cerebral hema- } \\
\text { toma }(p=0.03) \text {. nDNA concentrations } \\
\text { predict } 6 \text {-mo mortality (OR: } 1.6,95 \% \mathrm{Cl} \text { : } \\
1.1-2.4 ; p=0.03 \text { ) and } 6 \text {-mo RS score }>2 \\
\text { (OR: } 1.8,95 \% \mathrm{Cl}: 1.0-3.3 ; p=0.05)\end{array}$ \\
\hline Geiger et $a^{235}$ & 2006 & $\begin{array}{l}63 \text { patients with stroke } \\
\text { observed daily during the } \\
\text { first week }\end{array}$ & Nucleosomes & $\begin{array}{l}\text { In patients with } \mathrm{BI} \text { score } \geq 50 \text {, the increase } \\
\text { in nucleosomes is prolonged until day } 5 \text {. } \\
\text { Patients with } \mathrm{BI} \text { score }<50 \text { showed a } \\
\text { steeper initial increase with a maximum on } \\
\text { day } 3 \text {. Both days after stroke and } \mathrm{BI} \text { score } \\
\text { significantly influenced nucleosome con- } \\
\text { centrations ( } p<0.001 \text { for both). Nucleo- } \\
\text { some concentration showed a significant } \\
\text { correlation on day } 3 \text { with infarction volume } \\
(p=0.001)\end{array}$ \\
\hline Lam et al ${ }^{236}$ & 2006 & $\begin{array}{l}44 \text { patients aged } \geq 18 \text { y } \\
\text { presenting to the ED with a } \\
\text { stroke-like syndrome but } \\
\text { negative neuroimaging } \\
\text { results }\end{array}$ & nDNA & $\begin{array}{l}\text { Patients with post-stroke mRS grades } 3-6 \\
\text { have been shown with a nDNA concentra- } \\
\text { tion significantly higher than that of } \\
\text { patients with post-stroke mRS grades } 0-2 \\
(p=0.01) \text {. nDNA concentration could } \\
\text { predict post-stroke morbidity and mortal- } \\
\text { ity in patients with negative neuroimaging }\end{array}$ \\
\hline Geiger et al ${ }^{237}$ & 2007 & $\begin{array}{l}63 \text { patients with stroke } \\
\text { observed daily during the } \\
\text { first week }\end{array}$ & Nucleosomes & $\begin{array}{l}\text { Levels of nucleosomes at days } 3 \text { and } 6 \\
\text { correlated significantly with initial } \mathrm{BI} \\
(p=0.0023 \text { and } 0.0284 \text {, respectively) and } \\
\text { with infarction volume only at day } 3 \\
(p=0.0001) \text {. Strong correlations have } \\
\text { been shown between } \mathrm{BI} \text { at admission and } \\
\mathrm{BI} \text { at discharge and between } \mathrm{BI} \text { at admis- } \\
\text { sion and infarction volume }(p<0.0001 \text { for } \\
\text { both). In patients with initially severe } \\
\text { defects (BI <50), nucleosomes at day } 3 \\
\text { have been found to be prognostically } \\
\text { relevant ( } p=0.014) \text {. In multivariate } \\
\text { analysis, nucleosomes and BI at admission } \\
\text { showed independent prognostic relevance } \\
(p=0.039)\end{array}$ \\
\hline Tsai et al ${ }^{238}$ & 2011 & $\begin{array}{l}50 \text { AIS patients and } \\
50 \text { control subjects }\end{array}$ & $\begin{array}{l}\text { nDNA and } \\
\text { mDNA }\end{array}$ & $\begin{array}{l}\text { Levels of nDNA and mDNA were higher in } \\
\text { patients with AIS than in controls } \\
(p<0.05) \text {. Elevated circulating nDNA in } \\
\text { plasma persisted until } 1 \text { mo after AIS. } \\
\text { Levels of nDNA positively correlated with } \\
\text { the clinical severity of stroke according to } \\
\text { NIHSS score }\end{array}$ \\
\hline Hirose et $\mathrm{al}^{239}$ & 2014 & $\begin{array}{l}49 \text { critically ill patients } \\
\text { admitted to ICU, of whom } \\
8 \text { with stroke }\end{array}$ & DNA, citH3 & $\begin{array}{l}\text { DNA has been found elevated in patients } \\
\text { with stroke with respect to controls. citH3 } \\
\text { has been detected in blood smears by } \\
\text { immunofluorescence }\end{array}$ \\
\hline Thålin et $\mathrm{al}^{240}$ & 2016 & $\begin{array}{l}31 \text { patients with } \\
\text { ischemic stroke }\end{array}$ & DNA, citH3 & $\begin{array}{l}\text { Patients with concurrent hsTnT elevation } \\
\text { revealed cerebral micro-thrombosis with } \\
\text { citH3 in thrombi in a higher rate than } \\
\text { controls }(p<0.001) \text {. citH3 correlated } \\
\text { positively with thrombin-antithrombin } \\
\text { complex }(p=0.004) \text { and soluble } \\
\text { P-selectin }(p<0.001)\end{array}$ \\
\hline
\end{tabular}


Table 3 (Continued)

\begin{tabular}{|c|c|c|c|c|}
\hline Author & Year & Patients & Biomarkers & Results \\
\hline Vallés et al ${ }^{96}$ & 2017 & $\begin{array}{l}243 \text { patients with AIS } \\
\text { followed up for } 12 \text { mo after } \\
\text { the event }\end{array}$ & $\begin{array}{l}\text { dsDNA, } \\
\text { nucleosomes, } \\
\text { citH3 }\end{array}$ & $\begin{array}{l}\text { dsDNA, nucleosomes and citH3 were } \\
\text { significantly higher among patients with } \\
\text { AIS compared with healthy subjects } \\
\text { ( } p<0.05 ; p<0.001 \text { for the latter). These } \\
\text { parameters were increased in patients who } \\
\text { were older than } 65 \text { y ( } p<0.001) \text {, in those } \\
\text { with a history of AF ( } p=0.013 \text { for dsDNA, } \\
p=0.007 \text { for citH3, } p=0.02 \text { for nucleo- } \\
\text { somes), CE stroke }(p<0.05 \text { for dsDNA and } \\
\text { citH3), high glucose levels ( } p<0.05 \text { for all } \\
\text { markers) and severe stroke scores at } \\
\text { admission ( } p<0.001 \text { for all markers) and } \\
\text { discharge ( } p<0.001 \text { for citH3 and } \\
\text { nucleosomes, } p=0.038 \text { for dsDNA). In } \\
\text { multivariate analysis, elevated levels of } \\
\text { citH3 at onset was independently } \\
\text { associated with AF (OR: } 6.704,95 \% \text { Cl: } \\
1.4-32.1 ; p=0.017 \text { ) and with all-cause } \\
\text { mortality at } 1 \text {-year follow-up (OR: } 7.055 \text {, } \\
95 \% \text { Cl: } 1.631-30.50 ; p=0.009)\end{array}$ \\
\hline Laridan et al ${ }^{241}$ & 2017 & $\begin{array}{l}68 \text { ischemic stroke patients } \\
\text { undergoing endovascular } \\
\text { treatment }\end{array}$ & DNA, citH3 & $\begin{array}{l}\text { citH3 was observed in almost all thrombi } \\
\text { and co-localized with extracellular DNA } \\
\text { released from neutrophils. citH3 was more } \\
\text { abundant in thrombi of CE origin com- } \\
\text { pared with other etiologies ( } p<0.05) \text {. } \\
\text { Older thrombi contained significantly } \\
\text { more neutrophils and citH3 compared } \\
\text { with fresh thrombi ( } p<0.001 \text { and } \\
p<0.05 \text {, respectively) }\end{array}$ \\
\hline
\end{tabular}

Abbreviations: AF, atrial fibrillation; AIS, acute ischemic stroke; AUC, area under the curve; BI, Barthel index; CE, cardioembolic; CI, confidence interval; citH3, citrullinated histone H3; CRP, C-reactive protein; ds, double strain; ED, emergency department; hsTnT, high sensitive troponin T; mRS, modified Rankin scale; NIHSS, National Institutes of Health Stroke Scale; m, mitochondrial; n, nuclear; NET, neutrophil extracellular trap; NSE, neuron-specific enolase; OR, odds ratio.

the presentation of autoantigens to autoreactive $\mathrm{B}$ cells is enhanced. ${ }^{116,126}$ A leading role in SLE pathogenesis may be played by an alternative form of NETs, called mitochondrial DNA NETs. In fact, more severe forms of SLE have been observed in mice after injection of oxidized mitochondrial DNA and in humans carrying NOX-deficient genes (typically in CGD). 124,127 Although the role of NETs in SLE requires further investigations, their high levels found in the skin, kidney and bone marrow support a direct role in SLE-associated organ dysfunction ${ }^{123}$ and preliminary clinical studies support a potential association between circulating levels of NETs and disease activity (-Table 4). 116,123,125,128-131

\section{Rheumatoid Arthritis}

In RA, activated neutrophils are the most abundant cells in the synovial fluid. In addition, a wide number of anti-citrullinated proteins/peptides antibodies (ACPA) is produced in RA, representing specific disease markers. ${ }^{132}$ Both endogenous and exogenous antigens become target of ACPA after deimination (or citrullination), which is a post-translational modification largely catalysed by the PAD2 and 4, usually overexpressed in RA patients. ${ }^{133,134}$ A major contribution to the citrullination comes from NET generated from activated neutrophils, especially those belonging to the LDG subpopulation. ${ }^{118,135}$
Furthermore, deiminated histones have been recognized as key mechanism leading to ACPA generation in RA patients, especially those with Felty syndrome. ${ }^{59,136}$ Noteworthy, the ectopic lymphoid structures localized in the RA joint synovium may also contribute to the NET generation. They represent functional structures supporting the clonal selection of autoreactive $B$ cells and then their differentiation to plasma cells producing antibodies against citrullinated antigens. ${ }^{137-139}$ Therefore, a delay in the clearance of NETs might form a reservoir of citrullinated antigens, which sustain the autoimmune response in RA as already described for SLE. ${ }^{125}$

\section{ANCA-Associated Vasculitis}

ANCA-associated vasculitis (AAV) is referred to as a group of pauci-immune vasculitis characterized by neutrophil-rich necrotizing inflammation of small vessels and the presence of ANCAs. In this context, NETs have been recently found at the sites of vasculitic lesions (kidney and skin) and in thrombi, both as co-localizations of DNA and granule proteins and as mere citrullinated histones. ${ }^{112,140-145}$ Some cross-sectional studies compared NET levels during remission and active disease, although results remain inconclusive. ${ }^{146-148}$ Neutrophils from patients with AAV are less prone to undergo apoptosis and show spontaneous NET formation. Even though the high 
Table 4 Clinical evidence linking circulating NETs to clinical activity of autoimmune diseases

\begin{tabular}{|c|c|c|c|c|c|}
\hline Author & Year & Disease & Patients & Outcome & Result \\
\hline Hakkim et al ${ }^{125}$ & 2010 & SLE & $\begin{array}{l}\text { Lupus nephritis vs. } \\
\text { healthy controls }\end{array}$ & $\begin{array}{l}\text { Activity index on } \\
\text { renal biopsy }\end{array}$ & $\begin{array}{l}\text { Poor NET degradation was associated } \\
\text { with lupus nephritis and increased } \\
\text { serum levels of anti-dsDNA antibodies }\end{array}$ \\
\hline $\begin{array}{l}\text { Villanueva } \\
\text { et al }{ }^{123}\end{array}$ & 2011 & SLE & III or IV class GN & $\begin{array}{l}\text { Activity index on } \\
\text { renal biopsy }\end{array}$ & $\begin{array}{l}\text { Patients with class IV GN had higher } \\
\text { activity index (\% of netting neutrophils) } \\
\text { and higher circulating levels of } \\
\text { anti-dsDNA antibodies }\end{array}$ \\
\hline Leffler et al ${ }^{116}$ & 2012 & SLE & $\begin{array}{l}\text { Patients with disease } \\
\text { remission and } \\
\text { flare vs. healthy controls }\end{array}$ & Disease activity & $\begin{array}{l}\text { Low NET degradation was associated } \\
\text { with complement activation/deposi- } \\
\text { tion, high levels of circulating autoanti- } \\
\text { bodies and renal involvement (GN) }\end{array}$ \\
\hline Leffler et al $^{128}$ & 2013 & SLE & $\begin{array}{l}69 \text { patients followed up } \\
\text { for a median of } 784 \mathrm{~d}\end{array}$ & Disease activity & $\begin{array}{l}\text { Decreased ability to degrade NETs was } \\
\text { associated with clinical manifestations } \\
\text { in SLE according with the SLEDAI-2K } \\
\text { score }\end{array}$ \\
\hline $\begin{array}{l}\text { Nakazawa } \\
\text { et al }\end{array}$ & 2014 & $\begin{array}{l}\text { MPA } \\
\text { SLE }\end{array}$ & $\begin{array}{l}38 \text { patients with } \\
\text { MPA vs. } 23 \text { SLE vs. } 8 \\
\text { control subjects }\end{array}$ & $\begin{array}{l}\text { BVAS } \\
\text { SLEDAI-2K score }\end{array}$ & $\begin{array}{l}\text { Both MPA and SLE patients showed } \\
\text { reduced NET degradation. In MPA } \\
\text { patients, this ability correlated with } \\
\text { disease activity, while no correlation } \\
\text { was shown between NETs and disease } \\
\text { activity (SLEDAI-2K score) in SLE } \\
\text { patients }\end{array}$ \\
\hline Zhang et al ${ }^{130}$ & 2014 & SLE & $\begin{array}{l}54 \text { patients vs. } 43 \\
\text { control subjects }\end{array}$ & Lupus nephritis & $\begin{array}{l}\text { High circulating levels of cfDNA (marker } \\
\text { of NET dysregulation) was found in } \\
\text { patients with SLE and were associated } \\
\text { with markers of renal injury, such as } \\
24-h \text { urinary protein content }(r=0.350 \text {; } \\
p=0.013) \text {, serum albumin ( } r= \\
-0.500 ; p<0.001) \text {, and creatinine } \\
\text { clearance }(r=-0.354 ; p=0.044)\end{array}$ \\
\hline $\begin{array}{l}\text { Pérez-Sánchez } \\
\text { et al }{ }^{131}\end{array}$ & 2017 & RA & $\begin{array}{l}106 \text { patients vs. } 40 \\
\text { control subjects }\end{array}$ & $\begin{array}{l}\text { RF, ESR, CRP, } \\
\text { NO, cIMT }\end{array}$ & $\begin{array}{l}\text { RA patients exhibited enhanced NET } \\
\text { generation and impaired DNase activity. } \\
\text { Furthermore, NETosis-derived products, } \\
\text { such as cfDNA, correlated with autoim- } \\
\text { mune parameters, inflammatory } \\
\text { mediators, oxidative stress markers as } \\
\text { well as early atherosclerosis }\end{array}$ \\
\hline
\end{tabular}

Abbreviations: BVAS, Birmingham vasculitis activity score; cfDNA, cell-free DNA; cIMT, carotid intima media thickness; CRP, C-reactive protein; dsDNA, double-stranded DNA; ESR, erythrocyte sedimentation rate; GN, glomerulonephritis; NET, neutrophil extracellular trap; NO, nitric oxide; MPA, microscopic polyangiitis; RA, rheumatoid arthritis; RF, rheumatoid factor; SLE, systemic lupus erythematosus; SLEDAI-2K, Systemic Lupus Erythematosus Disease Activity Index 2000.

fraction of LDGs observed in AAV may explain this behaviour, normal-density neutrophils have also been found to spontaneously release more NETs as compared with healthy blood donors. ${ }^{149}$ A growing body of data indicates ANCAs not only as neutrophil activators but also as promoters of NET generation. As neutrophil activation is epitope specific, epitope specificity and affinity are found increased during active disease. ${ }^{150-152}$ In turn, the overproduction of NETs enhanced the exposition of epitopes (MPO end proteinase-3), further perpetuating the generation of ANCAs. ${ }^{129,140}$ Alongside, elevated levels of NETs in AAV patients may be explained by a reduced NET clearance as confirmed by in vitro experiments. ${ }^{129}$

\section{Other Autoimmune Diseases}

Recent evidence links NETs and antiphospholipid (aPL) antibody syndrome (APS). High levels of dsDNA and NETs have been found in patients with APS and the serum of those patients display defective NET degradation. ${ }^{153,154}$ More specifically, aPL antibodies from patients with APS may induce the release of NETs from control neutrophils and especially LDGs. ${ }^{154}$ Also, thrombi from mice treated with APS IgG have been recently found to be enriched of citrullinated histone $\mathrm{H} 3$, thus indicating a role for NETs in thrombotic complications of APS. ${ }^{155}$ Further supporting a direct role in thrombosis, growing data linked NETs to preeclampsia, also in aPL-negative patients. ${ }^{156-158}$ Finally, NETosis has also been observed in psoriatic skin lesions. By inducing the expression of human $\beta$-defensin-2 in keratinocytes, NETs amplify the local inflammation leading to DC activation and consequent development of Munro's abscess. ${ }^{159,160}$ Finally, a direct correlation between the amount of NETs in the peripheral blood and disease severity has also been demonstrated. ${ }^{160}$ 


\section{Gout and Inflammatory Bowel Diseases}

Actually, very little is known about the link between NETs and gout and inflammatory bowel diseases (IBDs), such as Crohn's disease (CD) and ulcerative colitis (UC). In gout, NETs have been described not only to feed inflammation, ${ }^{161}$ but also to regulate the inflammatory process and block gout episodes. ${ }^{162}$ NET generation is responsible for the reduction of neutrophil density, then DNA nets encapsulate monosodium urate crystals protecting them from further phagocytosis, and finally NET-derived proteases block cytokines. ${ }^{163,164}$

NET formation has been poorly studied in IBDs. As ROS levels are elevated, it is likely that neutrophils could produce NETs. In UC, NETs have been observed and correlated with inflammation by proteomic studies, but more studies are warranted to clarify the NET involvement in both $\mathrm{CD}$ and UC. ${ }^{165}$ In 2016, He et al evaluated the role of NETs in IBDs. The authors found that NETs were generated by peripheral blood neutrophils from patients with active IBD; however, stimulation with sera from patients with active disease also induced significantly NET release on neutrophils isolated from healthy subjects. Moreover, NETs along with phosphatidylserine (PS) exposure on platelets, leukocytes and endothelial cells are involved in the hypercoagulability characterizing active IBD. The researchers also proved an inhibitory effect of lactadherin and DNase I on PS and NETs, separately, suggesting new targets for IBD drugs in next studies. ${ }^{166}$

\section{NETs and Lung Diseases}

In the last decade, the formation of NETs has drawn great attention concerning lung diseases. Components of NETs have been shown to damage both epithelial and endothelial cells as well as connective tissue worsening the lung pathology. ${ }^{167}$ Indeed, NETs have been identified in the lung of patients suffering from cystic fibrosis (CF), transfusionrelated acute lung injury (TRALI), asthma, chronic obstructive pulmonary disease (COPD), and in lungs infected with bacteria, virus, or fungi. ${ }^{168}$ In these pulmonary diseases, NETs have been described as emerging pathophysiological players of potential therapeutic interest.

\section{Cystic Fibrosis}

In CF, patients with high levels of free DNA in the sputum have been shown with a diminished lung function as compared with those with mild disease, because the airway obstruction is mainly a consequence of the amount of NETs and DNA. ${ }^{161}$ Marcos et al recently confirmed this finding, showing that free CF airway DNA levels correlated with pulmonary obstruction both in CF patients and mice. ${ }^{162}$ The importance of NETs in CF is highlighted by the fact that the elimination of free DNA from patient's airways is considered as an important therapeutic option. In fact, in both early and mild stages of the disease, NETs can provide extracellular antibacterial and antifungal host defences. At this time, recombinant inhaled DNase should be used more cautiously, being potentially responsible for the delivery of encaptured pathogens. Differently, in moderate to severe stages of CF, the amount of mucus and DNA was responsible for airway obstruction, which can be efficiently resolved by DNase by cleaving DNA traps. ${ }^{162,169}$ Moreover, isolates of Pseudomonas aeruginosa can trigger a great respiratory burst and NET release in CF. ${ }^{170} P$. aeruginosa-mediated NET formation was found responsible for the bactericidal permeability-increasing (BPI) protein cleavage by P. aeruginosa elastase, suggesting a novel mechanism in the development of autoimmunity to BPI. ${ }^{171}$ Moreover, the authors also provided a role for autoimmunity in CF disease severity, as autoantibody levels have been associated with diminished lung function.

\section{Chronic Obstructive Pulmonary Disease}

Neutrophil elastase has been detected in the airway mucosa of COPD patients during severe exacerbations showing a proinflammatory role via the secretion of CXCL8, which is a powerful NET inducer. ${ }^{172}$ In the sputum from acutely exacerbated COPD patients, NETs and NETotic neutrophils have been found in a great amount by confocal laser microscopy and electron microscopy; an abundance of NE and citH3 has also been demonstrated. ${ }^{173}$ These findings witness that NETosis can be considered as a part of COPD pathology, relevant for new therapeutic options. Anyway, NETs have been described in the airways of stable COPD patients as a marker of neutrophils in the sputum. ${ }^{174,175}$ In particular, a positive correlation between the abundance of NETs in the sputum of COPD patients and disease severity has been described; in fact, more than $90 \%$ of exacerbated COPD patients presented with a higher number of NETs in their sputum with respect to stable COPD patients. Indeed, the NET amount directly correlated with the disease severity in terms of airflow limitation. ${ }^{176}$ Recently, levels of NETs in the sputum of COPD patients have been directly associated with the severity of the disease and the number of exacerbations as well as with the loss of microbiota diversity and impaired ex vivo neutrophil phagocytosis. ${ }^{177}$ In this view, NETs could be an interesting therapeutic target in the future, considering that the only effective drugs are currently long-acting bronchodilators, which do not affect inflammation.

\section{Asthma}

Asthma has been classically considered as an eosinophilic disease. However, recent data claim that some asthmatic patients show an important neutrophilic inflammation in the lungs. Patients with "neutrophilic" asthma have shown a reduced response to the classical therapy with glucocorticoids, which in turn aggravate local inflammation by increasing neutrophil survival. ${ }^{178}$

In addition, glucocorticoid administration to neutrophilic asthmatics could aggravate lung inflammation, since glucocorticoids can prolong neutrophil survival. Since the hypothesis of autoimmune involvement in asthma has gained great interest recently, NETs have been demonstrated as key players in the stimulation of airway epithelial cells to produce autoantigens, especially in severe asthma, as antibodies against NE or MPO attenuated these effects. ${ }^{179}$ Dworski et al have shown that eosinophils in the airways of atopic asthmatic individuals could release eosinophil ETs and co- 
localized with eosinophil granule proteins, such as major basic protein and eosinophil cationic protein. ${ }^{180}$ In this case, DNA was of mitochondrial origin, and not nuclear. ${ }^{181}$ Interestingly, allergens did not show any increase in eosinophil ET or NET formation in the airways of asthmatic patients. ${ }^{180}$ Recently, eosinophils from asthmatic mice have been demonstrated to release eosinophil ETs co-localizing with eosinophil peroxidase aggravating pulmonary impairment, which was reversed by DNase therapy. ${ }^{182}$ Recombinant human DNase treatment improved resistance and decreased oxidative stress in the lungs of asthmatic mice. ${ }^{183}$ In light of this, a combined use of recombinant human DNase therapy along with inhaled glucocorticoids may provide a reduction in sputum viscosity and improve the quality of life and prognosis of these patients.

\section{Transfusion-Related Acute Lung Injury}

TRALI is the leading cause of blood transfusion-related death developing within 6 hour of transfusion and presenting with hypoxemia, respiratory distress, and pulmonary infiltrates. In 2012, Thomas et al demonstrated that NETs form during TRALI both in humans and in mice and that their degradation by DNase 1 inhalation improved the condition of mice with TRALI. ${ }^{184}$ Also, platelets can accumulate in the lungs of mice with TRALI and have been described to induce NET formation. ${ }^{185}$ In turn, histones expressed by NETs may activate platelets, thus feeding a vicious cycle. ${ }^{186}$ As a further proof of it, the pre-treatment of mice with a histone-blocking antibody decreased NET generation as well as lung oedema, lung vascular permeability, and mortality. ${ }^{185}$

\section{NETs and Cancer}

Neutrophils are known to be present inside and around solid cancers since long time, thus being the most representative tumour-infiltrating immune cells. Anyway, controversies have been raised about their role in this setting and two subsets of tumour-associated neutrophils (TANs) have been found to develop depending on the influences of the tumour microenvironment: the N1 phenotype displays proinflammatory and antitumourigenic functions, while the N2 phenotype has protumorigenic activity with transforming growth factor- $\beta$ produced by the local tumour microenvironment playing a central role in polarizing mature neutrophils to adopt a pro-tumour N2 phenotype. ${ }^{187}$ Many questions are open about NET's function in tumour growth modulation, even if a role for NETs has been recognized in the local tumour development and especially in tumour-associated thrombosis.

The first finding of a role for NETs in tumours dates back to 2013 based on a small number of Ewing's sarcoma samples suggesting that patients with intratumoral NETs experienced a poorer prognosis. ${ }^{188}$ A stronger suggestion for a role of NETs in tumour progression comes from studies investigating NET-associated proteins, such as NE and MPO. NE can directly impact on tumour growth, progression, and cell migration by inducing cell proliferation in both human and mouse adenocarcinoma cell lines. ${ }^{189}$ In addition, NE deficiency has been found to blunt tumour burden in mice. ${ }^{189}$ Although these results mainly referred to the soluble NE, they suggest a potential role for NETs, which need to be clarified by targeted study. Sangaletti et al found that NETs could stimulate the proliferation and malignant transformation of $B$ cells toward malignant lymphoma via the NF-KB signaling. ${ }^{190}$ A role for NETs has also been tested in pancreatic ductal adenocarcinoma. ${ }^{191}$ Another NET-associated protein involved in the pathophysiology of cancers is MMP-9, which contributes to carcinogenesis, tumour growth and progression, and metastasis. Apart from its role in different cancer types, it is still controversial whether NET-bound MMP-9 conveys these effects or NETs can even protect from MMP-9 functions; the reason of this controversy can be found in the fact that MMP-9 has been shown to be inactive when bound to NETs. ${ }^{192}$ Since IL-8 has been demonstrated to play a role in NET generation and angiogenesis, a clear clinical relevance for IL-8 in tumour progression has been shown for many tumours, too. ${ }^{193,194}$ The cascade including IL- 8 can be probably considered a vicious cycle started by NETs themselves recruiting additional neutrophils, which in turn produce NETs, all this ultimately concluding with tumour growth and angiogenesis. Demers et al have recently linked tumour progression and NETosis by showing that priming of neutrophils by tumour-associated granulocyte-colony stimulating growth factor (G-CSF) is able to promote tumour growth. Indeed, PAD4-deficiency was protective only against tumour progression when the implanted tumour cell line produced G-CSF. ${ }^{195}$

Various studies have confirmed a role for TANs in the enhancement of cancer cell survival, migration and poor prognosis, but none of this has focused on tumour-associated NETs. ${ }^{196-198}$ Interestingly, in vivo evidence from cutaneous melanoma has shown that it becomes more aggressive and metastatic after ultraviolet radiation because of neutrophil recruitment. In fact, neutrophil recruitment has been associated with a more migratory phenotype, local angiogenesis and angiotropism of melanoma cells, ${ }^{199}$ with a possible responsibility for NETosis, although NETs have not been specifically focused.

CXCL8 can also play a role in tumour-associated thrombosis as it is contained in microparticles. In the granulocytic subset of myeloid-derived suppressor cells (considered an important T-cell immunosuppressive component in cancerbearing hosts), IL-8 has been shown to stimulate the formation of NETs. ${ }^{200}$ Interestingly, tumour-derived microparticles can interact with macrophages, activating them, and promote the production of tumour necrosis factor- $\alpha$ favouring the recruitment of other inflammatory cells and NETs. ${ }^{201}$

vWF is a known actor in metastasis and tumour growth and the interaction with NETs can result deleterious. In mice models, vWF null mice or mice treated with antiglycoprotein Ib $\alpha$ experienced increased experimental lung metastasis. ${ }^{202,203}$ NETs have been demonstrated to bind to vWF on the vessel wall and this is important when considering that melanoma cells can stimulate endothelial cells to produce vWF contributing to thrombosis. ${ }^{204}$ 
In 2016, Guglietta et al investigated about the role of complement in NET induction and tumour growth. In a spontaneous small intestine cancer model, hypercoagulation can directly affect neutrophil effector function and is linked to complement activation, in particular C3a, showing an increased number of TANs and low-density neutrophils. LDGs displayed features of N2 neutrophils and spontaneously underwent NETosis, which was dependent on the involvement of the complement receptor C3aR. To block this reaction, the immune system triggers the development of neutrophils with an N2 phenotype, which are responsible for tumour growth in a mutation-dependent protumorigenic milieu. ${ }^{205}$

A role for NETs has been hypothesized for metastasis, too, even if specific studies are still lacking. Neutrophils per se promote the blocking of circulating tumour cells, especially under inflammatory conditions, and NETs are very important in this setting. ${ }^{206}$ Anyway, even considering other studies with DNase I suppressing tumorigenesis, the activation of peripherals cells as a result of tumour-induced intravascular NET formation, which predisposes for metastasis, is still a matter of debate. Platelet-granulocyte complexes with tumour cells not clearly identified as NETs have been proved to create early metastatic niches, which are pivotal for later metastatic progression. ${ }^{207}$ Upon the secretion of CXCL5 and CXCL7 by platelets due to contact with platelets and the release of IL-8 from tumour cells recruiting neutrophils, the tethering of tumour cells to endothelium takes place, leading to transendothelial migration first and the following development of metastasis. ${ }^{208}$ Main roles of NETs in cancer are summarized in - Fig. 2.

\section{Future Perspectives}

Accumulating data on the role of NETs in highly prevalent inflammatory conditions (such as sepsis, CV diseases, autoimmune and inflammatory diseases) pave the way to novel biomarkers and treatments, which might readily become available for patient care. However, their translation into the clinical practice requires further investigations specifically focused on NET biology and measurement assay. First, molecules integrated in NETs may vary according to environmental factors, so that the characterization of NET proteome represents an exciting challenge for the next future. Second, the low
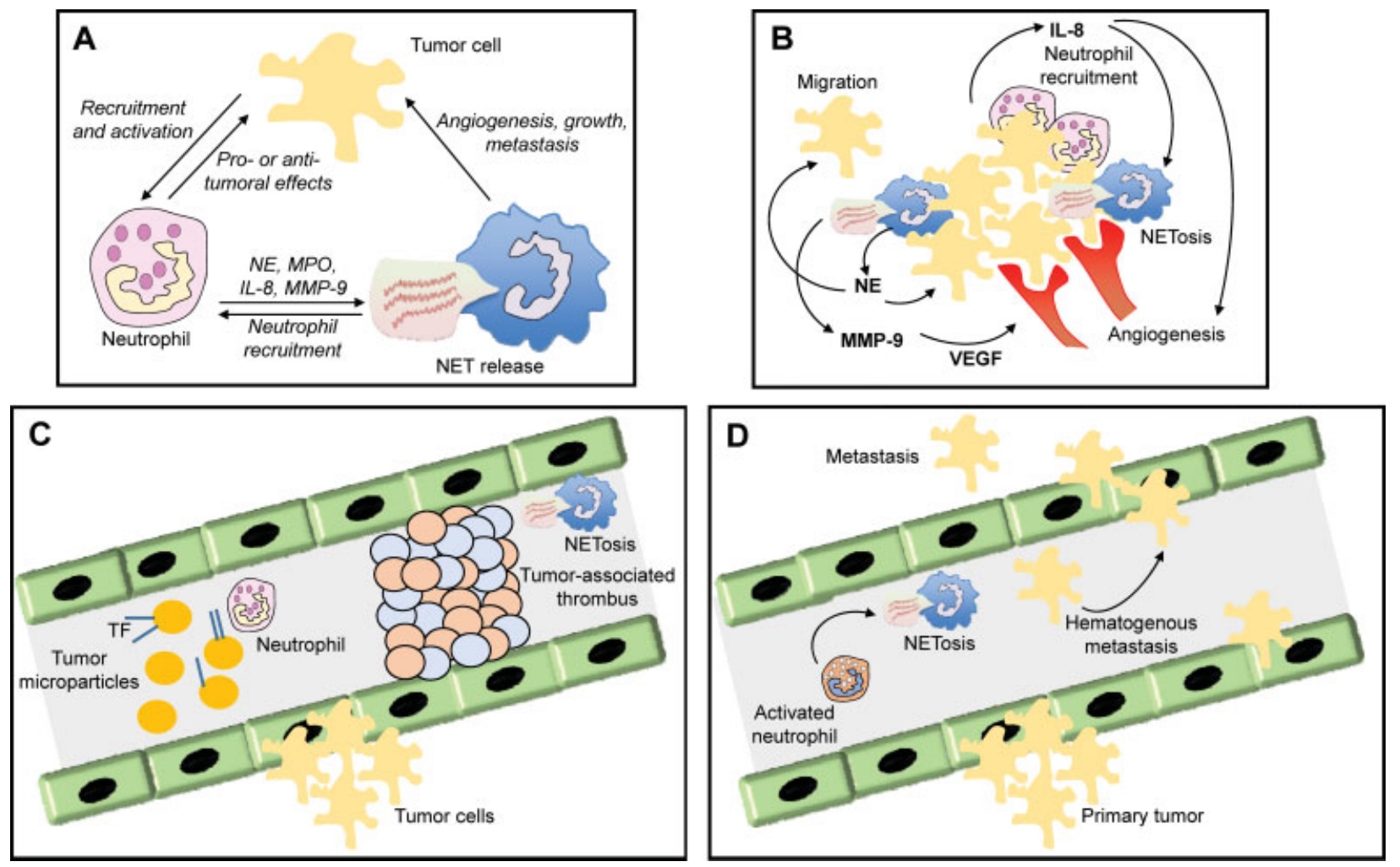

Fig. 2 The complex interplay between neutrophils and cancer. (A) Interactions between neutrophils and tumour cells lead to neutrophil extracellular trap (NET) production, which influence tumour growth and progression, angiogenesis and metastasis. In fact, tumour cells can recruit and activate neutrophils, acquiring pro- and antitumoural properties. Neutrophils are also responsible for cytokine secretion promoting the formation of NETs, which present a variety of antimicrobial and cytotoxic substances relevant for tumour growth and progression. (B) NETs may influence the local growth and progression of cancer. Neutrophil elastase (NE) is known to stimulate tumour growth, progression and spreading. Interleukin (IL)-8 is responsible for angiogenesis, which in turn is fed by the vascular endothelial growth factor (VEGF) from the extracellular matrix enhanced by matrix metalloproteinase (MMP)-9. NETs themselves can recruit other neutrophils amplifying local inflammatory reaction. (C) NETs are known to trigger tumour-associated thrombosis. Indeed, cancer stimulates the release of NETs via the production of granulocyte colony-stimulating factor (G-CSF) or the so-called tumour microparticles with tissue factor (TF) bound on their surface. Since NETs are prothrombotic, their increased production fuels this vicious circle along with the interaction with von Willebrand factor anchored to the vessel wall. Besides, NET-bound NE can inactivate TF pathway inhibitor, ultimately leading to TF-dependent coagulation. (D) NETs have been described to have a role in haematogenous metastasis. NET formation within capillaries may provide a scaffold for metastasizing tumour cells, although early adhesive events represent only a part of known mechanisms. 
activation threshold of neutrophils allows a ready availability of NETs, but this limits the development of strong, easy and cheap diagnostic assay. ${ }^{209}$ The lack of validation of NET assay methods might then explain the contrasting results observed so far in clinical studies. So far, (1) analytical assays (either fluorimetry or enzyme-linked immunosorbent assay [ELISA]) for NET products, (2) confocal microscopy of neutrophil enzymes and extracellular DNA networks and (3) flow cytometry based on nuclear morphology or citrullinated histones and DNA are the main approaches used for NET detection and (semi)-quantification. ${ }^{209}$ Furthermore, a standardization of methods and thresholds identifying an increased NET formation is needed. ELISA of plasma samples is likely the method meeting robustness, reproducibility, and easiness criteria for NET quantification. However, ELISA is not yet able to discriminate between increased generation and defective clearance of NETs. Furthermore, caution should be paid to avoid postsampling NET generation, as many physical and chemical stimuli may impact on neutrophil activation. ${ }^{210}$

On the contrary, many concerns exist on considering NETs as a selective therapeutic target. This is largely due to the critical role of NETs as first-line response to infectious agents. Nonetheless, in experimental PAD4 ${ }^{-1-}$ mouse, blocking NETosis is indicated as a relatively safe approach, characterized by normal survive in septic shock and better outcome after severe sterile inflammation. ${ }^{26}$ According to experimental data, many conventional therapies used for inflammatory diseases revealed inhibitory properties on NET cascade. Reduced NET generation may occur during treatment with ROS scavengers, such as $\mathrm{N}$-acetyl cysteine. ${ }^{211}$ Two small studies reported a clinical benefit of treatment with $\mathrm{N}$-acetyl cysteine in patients with SLE. ${ }^{212,213}$ Similarly, other conventional treatment used for the treatment of SLE, such as vitamin D and chloroquine, have been found to prevent NET generation. ${ }^{214,215}$ Alongside known agents, NET cascade might be inhibited by monoclonal antibodies targeting B cells (rituximab), ${ }^{216,217}$ complement system (eculizumab) $)^{218-220}$ and potentially IFN- $\alpha$ (sifalimumab and rontalizumab). ${ }^{221}$ More recently, $\mathrm{Cl}$-amidine, a PAD inhibitor, has been tested in mice. The suppression of NET generation induced by $\mathrm{Cl}$-amidine was associated with improvement of immune complex deposition and organ injury in mouse models of SLE and RA. ${ }^{222-224}$ Similarly, the inhibitory effect of $\mathrm{Cl}$-amidine on NET formation has been demonstrated to reduce atherosclerosis burden, arterial thrombosis and ischaemia/reperfusion injury in mice. ${ }^{84,225}$

\section{Conclusion}

As depicted in the present narrative review, a growing body of evidence is accumulating on NETs. Although initially investigated in infectious diseases, research studies have expanded their activity in other settings, such as CV diseases, autoimmunity and cancer. Available findings on NETs let us think that they may become new biomarkers of disease activity, prognosis and potentially therapeutic targets. Although a shroud of mystery still surrounds NETs, we now have few answers to some topic questions concerning NET behaviour and a wide overview on their significant roles. However, still many efforts are requested to clarify different aspects of NETs in both infectious and noninfectious diseases, as the mighty neutrophil surprises every day for its unique features and protean biology.

\section{Authors' Contributions}

A.B. and L.L. equally contributed to this work as first authors. A.B. and L.L. conceived the review and designed its structure. A.B., L.L., F.C., A.V. and C.D-C. collected data and prepared the manuscript. F.M., F.D. and G.G.C. gave suggestions to enhance the manuscript. All authors approved the final version of the manuscript.

\section{Disclosure of interest}

All authors declare that they have no competing interest.

\section{Acknowledgements}

This study has been supported by a grant from the European Commission (FP7-INNOVATION I HEALTH-F22013-602114; Athero-B cell: Targeting and exploiting B cell function for treatment in cardiovascular disease) and a grant from the Swiss National Science Foundation to Dr. F. Montecucco (no. 310030_152639/1).

\section{References}

1 Brinkmann V, Reichard U, Goosmann C, et al. Neutrophil extracellular traps kill bacteria. Science 2004;303(5663):1532-1535

2 Yousefi S, Simon HU. NETosis - Does it really represent nature's "Suicide Bomber"? Front Immunol 2016;7:328

3 Demaurex N, Monod A, Lew DP, Krause KH. Characterization of receptor-mediated and store-regulated $\mathrm{Ca} 2+$ influx in human neutrophils. Biochem J 1994;297(Pt 3):595-601

4 Wang S, Wang Y. Peptidylarginine deiminases in citrullination, gene regulation, health and pathogenesis. Biochim Biophys Acta 2013;1829(10):1126-1135

5 Papayannopoulos V, Metzler KD, Hakkim A, Zychlinsky A. Neutrophil elastase and myeloperoxidase regulate the formation of neutrophil extracellular traps. J Cell Biol 2010;191(03):677-691

6 Yipp BG, Petri B, Salina D, et al. Infection-induced NETosis is a dynamic process involving neutrophil multitasking in vivo. Nat Med 2012;18(09):1386-1393

7 Sousa-Rocha D, Thomaz-Tobias M, Diniz LF, Souza PS, Pinge-Filho P, Toledo KA. Trypanosoma cruzi and its soluble antigens induce NET release by stimulating toll-like receptors. PLoS One 2015;10 (10):e0139569

8 Mohanty T, Sjögren J, Kahn F, et al. A novel mechanism for NETosis provides antimicrobial defense at the oral mucosa. Blood 2015;126(18):2128-2137

9 Nishinaka Y, Arai T, Adachi S, Takaori-Kondo A, Yamashita K. Singlet oxygen is essential for neutrophil extracellular trap formation. Biochem Biophys Res Commun 2011;413(01):75-79

10 Pilsczek FH, Salina D, Poon KK, et al. A novel mechanism of rapid nuclear neutrophil extracellular trap formation in response to Staphylococcus aureus. J Immunol 2010;185(12):7413-7425

11 Lewis HD, Liddle J, Coote JE, et al. Inhibition of PAD4 activity is sufficient to disrupt mouse and human NET formation. Nat Chem Biol 2015;11(03):189-191

12 Branitzki-Heinemann K, Möllerherm H, Völlger L, et al. Formation of neutrophil extracellular traps under low oxygen level. Front Immunol 2016;7:518

13 Neeli I, Khan SN, Radic M. Histone deimination as a response to inflammatory stimuli in neutrophils. J Immunol 2008;180(03): 1895-1902 
14 Carestia A, Kaufman T, Rivadeneyra L, et al. Mediators and molecular pathways involved in the regulation of neutrophil extracellular trap formation mediated by activated platelets. J Leukoc Biol 2016;99(01):153-162

15 Yousefi S, Mihalache C, Kozlowski E, Schmid I, Simon HU. Viable neutrophils release mitochondrial DNA to form neutrophil extracellular traps. Cell Death Differ 2009;16(11):1438-1444

16 Sørensen OE, Borregaard N. Neutrophil extracellular traps - the dark side of neutrophils. J Clin Invest 2016;126(05):1612-1620

17 Seper A, Hosseinzadeh A, Gorkiewicz G, et al. Vibrio cholerae evades neutrophil extracellular traps by the activity of two extracellular nucleases. PLoS Pathog 2013;9(09):e1003614

18 Ueki S, Melo RC, Ghiran I, Spencer LA, Dvorak AM, Weller PF. Eosinophil extracellular DNA trap cell death mediates lytic release of free secretion-competent eosinophil granules in humans. Blood 2013;121(11):2074-2083

19 Ueki S, Konno Y, Takeda M, et al. Eosinophil extracellular trap cell death-derived DNA traps: their presence in secretions and functional attributes. J Allergy Clin Immunol 2016;137(01):258-267

20 Morshed M, Hlushchuk R, Simon D, et al. NADPH oxidaseindependent formation of extracellular DNA traps by basophils. J Immunol 2014;192(11):5314-5323

21 Yousefi S, Morshed M, Amini P, et al. Basophils exhibit antibacterial activity through extracellular trap formation. Allergy 2015;70(09):1184-1188

22 von Köckritz-Blickwede M, Goldmann O, Thulin P, et al. Phagocytosis-independent antimicrobial activity of mast cells by means of extracellular trap formation. Blood 2008;111(06):3070-3080

23 Chow OA, von Köckritz-Blickwede M, Bright AT, et al. Statins enhance formation of phagocyte extracellular traps. Cell Host Microbe 2010;8(05):445-454

24 McDonald B, Urrutia R, Yipp BG, Jenne CN, Kubes P. Intravascular neutrophil extracellular traps capture bacteria from the bloodstream during sepsis. Cell Host Microbe 2012;12(03):324-333

25 Luo L, Zhang S, Wang Y, et al. Proinflammatory role of neutrophil extracellular traps in abdominal sepsis. Am J Physiol Lung Cell Mol Physiol 2014;307(07):L586-L596

26 Martinod K, Fuchs TA, Zitomersky NL, et al. PAD4-deficiency does not affect bacteremia in polymicrobial sepsis and ameliorates endotoxemic shock. Blood 2015;125(12):1948-1956

27 Clark SR, Ma AC, Tavener SA, et al. Platelet TLR4 activates neutrophil extracellular traps to ensnare bacteria in septic blood. Nat Med 2007;13(04):463-469

28 Gao X, Hao S, Yan H, Ding W, Li K, Li J. Neutrophil extracellular traps contribute to the intestine damage in endotoxemic rats. J Surg Res 2015;195(01):211-218

29 Allam R, Scherbaum CR, Darisipudi MN, et al. Histones from dying renal cells aggravate kidney injury via TLR2 and TLR4. J Am Soc Nephrol 2012;23(08):1375-1388

30 Czaikoski PG, Mota JM, Nascimento DC, et al. Neutrophil extracellular traps induce organ damage during experimental and clinical sepsis. PLoS One 2016;11(02):e0148142

31 Manda-Handzlik A, Bystrzycka W, Sieczkowska S, Demkow U, Ciepiela O. Antibiotics modulate the ability of neutrophils to release neutrophil extracellular traps. Adv Exp Med Biol 2017; 944:47-52

32 Aldridge AJ. Role of the neutrophil in septic shock and the adult respiratory distress syndrome. Eur J Surg 2002;168(04):204-214

33 Gonzalez DJ, Corriden R, Akong-Moore K, Olson J, Dorrestein PC, Nizet V. N-terminal ArgD peptides from the classical Staphylococcus aureus Agr system have cytotoxic and proinflammatory activities. Chem Biol 2014;21(11):1457-1462

34 Branzk N, Papayannopoulos V. Molecular mechanisms regulating NETosis in infection and disease. Semin Immunopathol 2013; 35(04):513-530

35 Bianchi M, Hakkim A, Brinkmann V, et al. Restoration of NET formation by gene therapy in CGD controls aspergillosis. Blood 2009;114(13):2619-2622
36 Berends ET, Horswill AR, Haste NM, Monestier M, Nizet V, von Köckritz-Blickwede M. Nuclease expression by Staphylococcus aureus facilitates escape from neutrophil extracellular traps. J Innate Immun 2010;2(06):576-586

37 Bogaert D, De Groot R, Hermans PW. Streptococcus pneumoniae colonisation: the key to pneumococcal disease. Lancet Infect Dis 2004;4(03):144-154

38 Chromek M, Slamová Z, Bergman P, et al. The antimicrobial peptide cathelicidin protects the urinary tract against invasive bacterial infection. Nat Med 2006;12(06):636-641

39 Mori Y, Yamaguchi M, Terao Y, Hamada S, Ooshima T, Kawabata S. $\alpha-$ Enolase of Streptococcus pneumoniae induces formation of neutrophil extracellular traps.J Biol Chem 2012;287(13):10472-10481

40 Wartha F, Beiter K, Albiger B, et al. Capsule and D-alanylated lipoteichoic acids protect Streptococcus pneumoniae against neutrophil extracellular traps. Cell Microbiol 2007;9(05):1162-1171

41 Beiter K, Wartha F, Albiger B, Normark S, Zychlinsky A, Henriques-Normark B. An endonuclease allows Streptococcus pneumoniae to escape from neutrophil extracellular traps. Curr Biol 2006;16(04):401-407

42 Buchanan JT, Simpson AJ, Aziz RK, et al. DNase expression allows the pathogen group A Streptococcus to escape killing in neutrophil extracellular traps. Curr Biol 2006;16(04):396-400

43 Walker MJ, Hollands A, Sanderson-Smith ML, et al. DNase Sda1 provides selection pressure for a switch to invasive group A streptococcal infection. Nat Med 2007;13(08):981-985

44 Uchiyama S, Andreoni F, Schuepbach RA, Nizet V, Zinkernagel AS. DNase Sda1 allows invasive M1T1 Group A Streptococcus to prevent TLR9-dependent recognition. PLoS Pathog 2012;8(06): e1002736

45 Kambas K, Mitroulis I, Apostolidou E, et al. Autophagy mediates the delivery of thrombogenic tissue factor to neutrophil extracellular traps in human sepsis. PLoS One 2012;7(09):e45427

46 Yan J, Meng X, Wancket LM, et al. Glutathione reductase facilitates host defense by sustaining phagocytic oxidative burst and promoting the development of neutrophil extracellular traps. J Immunol 2012;188(05):2316-2327

47 Neumann A, Berends ET, Nerlich A, et al. The antimicrobial peptide LL-37 facilitates the formation of neutrophil extracellular traps. Biochem J 2014;464(01):3-11

48 Khoruts A, Sadowsky MJ. Understanding the mechanisms of faecal microbiota transplantation. Nat Rev Gastroenterol Hepatol 2016;13(09):508-516

49 Möllerherm H, Neumann A, Schilcher K, et al. Yersinia enterocolitica-mediated degradation of neutrophil extracellular traps (NETs). FEMS Microbiol Lett 2015;362(23):fnv192

50 Ramos-Kichik V, Mondragón-Flores R, Mondragón-Castelán M, et al. Neutrophil extracellular traps are induced by Mycobacterium tuberculosis. Tuberculosis (Edinb) 2009;89(01):29-37

51 Braian C, Hogea V, Stendahl O. Mycobacterium tuberculosisinduced neutrophil extracellular traps activate human macrophages. J Innate Immun 2013;5(06):591-602

52 Saitoh T, Komano J, Saitoh Y, et al. Neutrophil extracellular traps mediate a host defense response to human immunodeficiency virus-1. Cell Host Microbe 2012;12(01):109-116

53 Hemmers S, Teijaro JR, Arandjelovic S, Mowen KA. PAD4-mediated neutrophil extracellular trap formation is not required for immunity against influenza infection. PLoS One 2011;6(07):e22043

54 Tripathi S, Verma A, Kim EJ, White MR, Hartshorn KL. LL-37 modulates human neutrophil responses to influenza $A$ virus. J Leukoc Biol 2014;96(05):931-938

55 Moreno-Altamirano MM, Rodríguez-Espinosa O, Rojas-Espinosa O, Pliego-Rivero B, Sánchez-García FJ. Dengue virus serotype-2 interferes with the formation of neutrophil extracellular traps. Intervirology 2015;58(04):250-259

56 Cortjens B, de Boer OJ, de Jong R, et al. Neutrophil extracellular traps cause airway obstruction during respiratory syncytial virus disease. J Pathol 2016;238(03):401-411 
57 Raftery MJ, Lalwani P, Krautkrämer E, et al. $\beta 2$ integrin mediates hantavirus-induced release of neutrophil extracellular traps. J Exp Med 2014;211(07):1485-1497

58 Urban CF, Reichard U, Brinkmann V, Zychlinsky A. Neutrophil extracellular traps capture and kill Candida albicans yeast and hyphal forms. Cell Microbiol 2006;8(04):668-676

59 Urban CF, Ermert D, Schmid M, et al. Neutrophil extracellular traps contain calprotectin, a cytosolic protein complex involved in host defense against Candida albicans. PLoS Pathog 2009;5 (10):e1000639

60 Bruns S, Kniemeyer O, Hasenberg M, et al. Production of extracellular traps against Aspergillus fumigatus in vitro and in infected lung tissue is dependent on invading neutrophils and influenced by hydrophobin RodA. PLoS Pathog 2010;6(04): e1000873

61 Rocha JD, Nascimento MT, Decote-Ricardo D, et al. Capsular polysaccharides from Cryptococcus neoformans modulate production of neutrophil extracellular traps (NETs) by human neutrophils. Sci Rep 2015;5:8008

62 Baker VS, Imade GE, Molta NB, et al. Cytokine-associated neutrophil extracellular traps and antinuclear antibodies in Plasmodium falciparum infected children under six years of age. Malar J 2008;7:41

63 Gabriel C, McMaster WR, Girard D, Descoteaux A. Leishmania donovani promastigotes evade the antimicrobial activity of neutrophil extracellular traps. J Immunol 2010;185(07):4319-4327

64 Guimarães-Costa AB, Nascimento MT, Froment GS, et al. Leishmania amazonensis promastigotes induce and are killed by neutrophil extracellular traps. Proc Natl Acad Sci U S A 2009; 106(16):6748-6753

65 Abi Abdallah DS, Lin C, Ball CJ, King MR, Duhamel GE, Denkers EY. Toxoplasma gondii triggers release of human and mouse neutrophil extracellular traps. Infect Immun 2012;80(02):768-777

66 Muñoz-Caro T, Mena Huertas SJ, Conejeros I, et al. Eimeria bovistriggered neutrophil extracellular trap formation is CD11b-, ERK 1/2-, p38 MAP kinase- and SOCE-dependent. Vet Res (Faisalabad) 2015;46:23

67 Behrendt JH, Ruiz A, Zahner H, Taubert A, Hermosilla C. Neutrophil extracellular trap formation as innate immune reactions against the apicomplexan parasite Eimeria bovis. Vet Immunol Immunopathol 2010;133(01):1-8

68 Muñoz Caro T, Hermosilla C, Silva LM, Cortes H, Taubert A. Neutrophil extracellular traps as innate immune reaction against the emerging apicomplexan parasite Besnoitia besnoiti. PLoS One 2014;9(03):e91415

69 Maksimov P, Hermosilla C, Kleinertz S, Hirzmann J, Taubert A. Besnoitia besnoiti infections activate primary bovine endothelial cells and promote PMN adhesion and NET formation under physiological flow condition. Parasitol Res 2016;115(05):1991-2001

70 Montecucco F, Lenglet S, Gayet-Ageron A, et al. Systemic and intraplaque mediators of inflammation are increased in patients symptomatic for ischemic stroke. Stroke 2010;41(07):1394-1404

71 von Brühl ML, Stark K, Steinhart A, et al. Monocytes, neutrophils, and platelets cooperate to initiate and propagate venous thrombosis in mice in vivo. J Exp Med 2012;209(04):819-835

72 Menegazzo L, Ciciliot S, Poncina N, et al. NETosis is induced by high glucose and associated with type 2 diabetes. Acta Diabetol 2015;52(03):497-503

73 Riyapa D, Buddhisa S, Korbsrisate S, et al. Neutrophil extracellular traps exhibit antibacterial activity against Burkholderia pseudomallei and are influenced by bacterial and host factors. Infect Immun 2012;80(11):3921-3929

74 Joshi MB, Lad A, Bharath Prasad AS, Balakrishnan A, Ramachandra L, Satyamoorthy K. High glucose modulates IL-6 mediated immune homeostasis through impeding neutrophil extracellular trap formation. FEBS Lett 2013;587(14):2241-2246

75 Carestia A, Frechtel G, Cerrone G, et al. NETosis before and after hyperglycemic control in type 2 diabetes mellitus patients. PLoS One 2016;11(12):e0168647
76 Martinod K, Witsch T, Erpenbeck L, et al. Peptidylarginine deiminase 4 promotes age-related organ fibrosis. J Exp Med 2017;214(02):439-458

77 Pálmai-Pallag T, Bachrati CZ. Inflammation-induced DNA damage and damage-induced inflammation: a vicious cycle. Microbes Infect 2014;16(10):822-832

78 Zhang Y, Guan L, YuJ, et al. Pulmonary endothelial activation caused by extracellular histones contributes to neutrophil activation in acute respiratory distress syndrome. Respir Res 2016;17(01):155

79 Michels A, Albánez S, Mewburn J, et al. Histones link inflammation and thrombosis through the induction of Weibel-Palade body exocytosis. J Thromb Haemost 2016;14(11):2274-2286

80 Carmona-Rivera C, Zhao W, Yalavarthi S, Kaplan MJ. Neutrophil extracellular traps induce endothelial dysfunction in systemic lupus erythematosus through the activation of matrix metalloproteinase-2. Ann Rheum Dis 2015;74(07):1417-1424

81 Gupta AK, Joshi MB, Philippova M, et al. Activated endothelial cells induce neutrophil extracellular traps and are susceptible to NETosis-mediated cell death. FEBS Lett 2010;584(14):3193-3197

82 Megens RT, Vijayan S, Lievens D, et al. Presence of luminal neutrophil extracellular traps in atherosclerosis. Thromb Haemost 2012;107(03):597-598

83 de Boer OJ, Li X, Teeling P, et al. Neutrophils, neutrophil extracellular traps and interleukin-17 associate with the organisation of thrombi in acute myocardial infarction. Thromb Haemost 2013;109(02):290-297

84 Knight JS, Luo W, O'Dell AA, et al. Peptidylarginine deiminase inhibition reduces vascular damage and modulates innate immune responses in murine models of atherosclerosis. Circ Res 2014;114(06):947-956

85 Warnatsch A, Ioannou M, Wang Q Papayannopoulos V. Inflammation. Neutrophil extracellular traps license macrophages for cytokine production in atherosclerosis. Science 2015;349(6245):316-320

86 Döring Y, Manthey HD, Drechsler M, et al. Auto-antigenic proteinDNA complexes stimulate plasmacytoid dendritic cells to promote atherosclerosis. Circulation 2012;125(13):1673-1683

87 Massberg S, Grahl L, von Bruehl ML, et al. Reciprocal coupling of coagulation and innate immunity via neutrophil serine proteases. Nat Med 2010;16(08):887-896

88 Savchenko AS, Borissoff JI, Martinod K, et al. VWF-mediated leukocyte recruitment with chromatin decondensation by PAD4 increases myocardial ischemia/reperfusion injury in mice. Blood 2014;123(01):141-148

89 Ge L, Zhou X, Ji WJ, et al. Neutrophil extracellular traps in ischemia-reperfusion injury-induced myocardial no-reflow: therapeutic potential of DNase-based reperfusion strategy. Am J Physiol Heart Circ Physiol 2015;308(05):H500-H509

90 Mangold A, Alias S, Scherz T, et al. Coronary neutrophil extracellular trap burden and deoxyribonuclease activity in ST-elevation acute coronary syndrome are predictors of ST-segment resolution and infarct size. Circ Res 2015;116(07):1182-1192

91 Stakos DA, Kambas K, Konstantinidis T, et al. Expression of functional tissue factor by neutrophil extracellular traps in culprit artery of acute myocardial infarction. Eur Heart J 2015; 36(22):1405-1414

92 Quillard T, Araújo HA, Franck G, Shvartz E, Sukhova G, Libby P. TLR2 and neutrophils potentiate endothelial stress, apoptosis and detachment: implications for superficial erosion. Eur Heart J 2015;36(22):1394-1404

93 Borissoff JI, Joosen IA, Versteylen MO, et al. Elevated levels of circulating DNA and chromatin are independently associated with severe coronary atherosclerosis and a prothrombotic state. Arterioscler Thromb Vasc Biol 2013;33(08):2032-2040

94 Kehrel BE, Fender AC. Resolving thromboinflammation in the brain after ischemic stroke? Circulation 2016;133(22):2128-2131

95 De Meyer SF, Denorme F, Langhauser F, Geuss E, Fluri F, Kleinschnitz $C$. Thromboinflammation in stroke brain damage. Stroke 2016;47(04):1165-1172 
96 Vallés J, Lago A, Santos MT, et al. Neutrophil extracellular traps are increased in patients with acute ischemic stroke: prognostic significance. Thromb Haemost 2017;117(10):1919-1929

97 Kannemeier C, Shibamiya A, Nakazawa F, et al. Extracellular RNA constitutes a natural procoagulant cofactor in blood coagulation. Proc Natl Acad Sci U S A 2007;104(15):6388-6393

98 Ammollo CT, Semeraro F, Xu J, Esmon NL, Esmon CT. Extracellular histones increase plasma thrombin generation by impairing thrombomodulin-dependent protein C activation. J Thromb Haemost 2011;9(09):1795-1803

99 Petersen LC, Bjørn SE, Nordfang O. Effect of leukocyte proteinases on tissue factor pathway inhibitor. Thromb Haemost 1992;67 (05):537-541

100 Brill A, Fuchs TA, Savchenko AS, et al. Neutrophil extracellular traps promote deep vein thrombosis in mice. J Thromb Haemost 2012;10(01):136-144

101 Fuchs TA, Brill A, Duerschmied D, et al. Extracellular DNA traps promote thrombosis. Proc Natl Acad Sci U S A 2010;107(36): 15880-15885

102 Ward CM, Tetaz TJ, Andrews RK, Berndt MC. Binding of the von Willebrand factor A1 domain to histone. Thromb Res 1997;86 (06):469-477

103 Fuchs TA, Bhandari AA, Wagner DD. Histones induce rapid and profound thrombocytopenia in mice. Blood 2011;118(13): 3708-3714

104 Martinod K, Demers M, Fuchs TA, et al. Neutrophil histone modification by peptidylarginine deiminase 4 is critical for deep vein thrombosis in mice. Proc Natl Acad Sci U S A 2013; 110(21):8674-8679

105 El-Sayed OM, Dewyer NA, Luke CE, et al. Intact Toll-like receptor 9 signaling in neutrophils modulates normal thrombogenesis in mice. J Vasc Surg 2016;64(05):1450-1458.e1

106 van Montfoort ML, Stephan F, Lauw MN, et al. Circulating nucleosomes and neutrophil activation as risk factors for deep vein thrombosis. Arterioscler Thromb Vasc Biol 2013;33(01):147-151

107 Diaz JA, Fuchs TA, Jackson TO, et al; for the Michigan Research Venous Group*. Plasma DNA is elevated in patients with deep vein thrombosis. J Vasc Surg Venous Lymphat Disord 2013;1(04): 341-348

108 Savchenko AS, Martinod K, Seidman MA, et al. Neutrophil extracellular traps form predominantly during the organizing stage of human venous thromboembolism development. J Thromb Haemost 2014;12(06):860-870

109 Gupta S, Kaplan MJ. The role of neutrophils and NETosis in autoimmune and renal diseases. Nat Rev Nephrol 2016;12 (07):402-413

110 Lande R, Ganguly D, Facchinetti V, et al. Neutrophils activate plasmacytoid dendritic cells by releasing self-DNA-peptide complexes in systemic lupus erythematosus. Sci Transl Med 2011;3 (73):73ra19

111 Garcia-Romo GS, Caielli S, Vega B, et al. Netting neutrophils are major inducers of type I IFN production in pediatric systemic lupus erythematosus. Sci Transl Med 2011;3(73):73ra20

112 Sangaletti S, Tripodo C, Chiodoni C, et al. Neutrophil extracellular traps mediate transfer of cytoplasmic neutrophil antigens to myeloid dendritic cells toward ANCA induction and associated autoimmunity. Blood 2012;120(15):3007-3018

113 Puga I, Cols M, Barra CM, et al. B cell-helper neutrophils stimulate the diversification and production of immunoglobulin in the marginal zone of the spleen. Nat Immunol 2011;13(02):170-180

114 Gehrke N, Mertens C, Zillinger T, et al. Oxidative damage of DNA confers resistance to cytosolic nuclease TREX1 degradation and potentiates STING-dependent immune sensing. Immunity 2013; 39(03):482-495

115 Kahlenberg JM, Carmona-Rivera C, Smith CK, Kaplan MJ. Neutrophil extracellular trap-associated protein activation of the NLRP3 inflammasome is enhanced in lupus macrophages. J Immunol 2013;190(03):1217-1226
116 Leffler J, Martin M, Gullstrand B, et al. Neutrophil extracellular traps that are not degraded in systemic lupus erythematosus activate complement exacerbating the disease. J Immunol 2012; 188(07):3522-3531

117 Liu CL, Tangsombatvisit S, Rosenberg JM, et al. Specific posttranslational histone modifications of neutrophil extracellular traps as immunogens and potential targets of lupus autoantibodies. Arthritis Res Ther 2012;14(01):R25

118 Khandpur R, Carmona-Rivera C, Vivekanandan-Giri A, et al. NETs are a source of citrullinated autoantigens and stimulate inflammatory responses in rheumatoid arthritis. Sci Transl Med 2013;5 (178):178ra40

119 Grayson PC, Kaplan MJ. At the bench: neutrophil extracellular traps (NETs) highlight novel aspects of innate immune system involvement in autoimmune diseases. J Leukoc Biol 2016;99 (02):253-264

120 Mahajan A, Herrmann M, Muñoz LE. Clearance deficiency and cell death pathways: a model for the pathogenesis of SLE. Front Immunol 2016;7:35

121 Courtney PA, Crockard AD, Williamson K, Irvine AE, Kennedy RJ, Bell AL. Increased apoptotic peripheral blood neutrophils in systemic lupus erythematosus: relations with disease activity, antibodies to double stranded DNA, and neutropenia. Ann Rheum Dis 1999;58(05):309-314

122 Denny MF, Yalavarthi S, Zhao W, et al. A distinct subset of proinflammatory neutrophils isolated from patients with systemic lupus erythematosus induces vascular damage and synthesizes type I IFNs. J Immunol 2010;184(06):3284-3297

123 Villanueva E, Yalavarthi S, Berthier CC, et al. Netting neutrophils induce endothelial damage, infiltrate tissues, and expose immunostimulatory molecules in systemic lupus erythematosus. J Immunol 2011;187(01):538-552

124 Lood C, Blanco LP, Purmalek MM, et al. Neutrophil extracellular traps enriched in oxidized mitochondrial DNA are interferogenic and contribute to lupus-like disease. Nat Med 2016;22(02):146-153

125 Hakkim A, Fürnrohr BG, Amann K, et al. Impairment of neutrophil extracellular trap degradation is associated with lupus nephritis. Proc Natl Acad Sci U S A 2010;107(21):9813-9818

126 Chauhan SK, Rai R, Singh VV, Rai M, Rai G. Differential clearance mechanisms, neutrophil extracellular trap degradation and phagocytosis, are operative in systemic lupus erythematosus patients with distinct autoantibody specificities. Immunol Lett 2015;168(02):254-259

127 Campbell AM, Kashgarian M, Shlomchik MJ. NADPH oxidase inhibits the pathogenesis of systemic lupus erythematosus. Sci Transl Med 2012;4(157):157ra141

128 Leffler J, Gullstrand B, Jönsen A, et al. Degradation of neutrophil extracellular traps co-varies with disease activity in patients with systemic lupus erythematosus. Arthritis Res Ther 2013;15 (04):R84

129 Nakazawa D, Shida H, Tomaru U, et al. Enhanced formation and disordered regulation of NETs in myeloperoxidase-ANCA-associated microscopic polyangiitis. J Am Soc Nephrol 2014;25(05): 990-997

130 Zhang S, Lu X, Shu X, et al. Elevated plasma cfDNA may be associated with active lupus nephritis and partially attributed to abnormal regulation of neutrophil extracellular traps (NETs) in patients with systemic lupus erythematosus. Intern Med 2014; 53(24):2763-2771

131 Pérez-Sánchez C, Ruiz-Limón P, Aguirre MA, et al. Diagnostic potential of NETosis-derived products for disease activity, atherosclerosis and therapeutic effectiveness in rheumatoid arthritis patients. J Autoimmun 2017;82:31-40

132 Corsiero E, Pratesi F, Prediletto E, Bombardieri M, Migliorini P. NETosis as source of autoantigens in rheumatoid arthritis. Front Immunol 2016; 7:485

133 Foulquier C, Sebbag M, Clavel C, et al. Peptidyl arginine deiminase type 2 (PAD-2) and PAD-4 but not PAD-1, PAD-3, and PAD-6 are 
expressed in rheumatoid arthritis synovium in close association with tissue inflammation. Arthritis Rheum 2007;56(11): 3541-3553

134 Spengler J, Lugonja B, Ytterberg AJ, et al. Release of active peptidyl arginine deiminases by neutrophils can explain production of extracellular citrullinated autoantigens in rheumatoid arthritis synovial fluid. Arthritis Rheumatol 2015;67(12):3135-3145

135 Wright HL, Makki FA, Moots RJ, Edwards SW. Low-density granulocytes: functionally distinct, immature neutrophils in rheumatoid arthritis with altered properties and defective TNF signalling. J Leukoc Biol 2017;101(02):599-611

136 Dwivedi N, Upadhyay J, Neeli I, et al. Felty's syndrome autoantibodies bind to deiminated histones and neutrophil extracellular chromatin traps. Arthritis Rheum 2012;64(04):982-992

137 Masson-Bessière C, Sebbag M, Durieux JJ, et al. In the rheumatoid pannus, anti-filaggrin autoantibodies are produced by local plasma cells and constitute a higher proportion of IgG than in synovial fluid and serum. Clin Exp Immunol 2000;119(03):544-552

138 Humby F, Bombardieri M, Manzo A, et al. Ectopic lymphoid structures support ongoing production of class-switched autoantibodies in rheumatoid synovium. PLoS Med 2009;6(01):e1

139 Croia C, Serafini B, Bombardieri M, et al. Epstein-Barr virus persistence and infection of autoreactive plasma cells in synovial lymphoid structures in rheumatoid arthritis. Ann Rheum Dis 2013;72(09):1559-1568

140 Kessenbrock K, Krumbholz M, Schönermarck U, et al. Netting neutrophils in autoimmune small-vessel vasculitis. Nat Med 2009;15(06):623-625

141 Yoshida M, Sasaki M, Sugisaki K, Yamaguchi Y, Yamada M. Neutrophil extracellular trap components in fibrinoid necrosis of the kidney with myeloperoxidase-ANCA-associated vasculitis. Clin Kidney J 2013;6(03):308-312

142 Tang S, Zhang Y, Yin SW, et al. Neutrophil extracellular trap formation is associated with autophagy-related signalling in ANCA-associated vasculitis. Clin Exp Immunol 2015;180(03): 408-418

143 O'Sullivan KM, Lo CY, Summers SA, et al. Renal participation of myeloperoxidase in antineutrophil cytoplasmic antibody (ANCA)associated glomerulonephritis. Kidney Int 2015;88(05):1030-1046

144 Nakazawa D, Tomaru U, Yamamoto C, Jodo S, Ishizu A. Abundant neutrophil extracellular traps in thrombus of patient with microscopic polyangiitis. Front Immunol 2012;3:333

145 Imamoto T, Nakazawa D, Shida H, et al. Possible linkage between microscopic polyangiitis and thrombosis via neutrophil extracellular traps. Clin Exp Rheumatol 2014;32(01):149-150

146 Söderberg D, Kurz T, Motamedi A, Hellmark T, Eriksson P, Segelmark M. Increased levels of neutrophil extracellular trap remnants in the circulation of patients with small vessel vasculitis, but an inverse correlation to anti-neutrophil cytoplasmic antibodies during remission. Rheumatology (Oxford) 2015;54(11): 2085-2094

147 Surmiak MP, Hubalewska-Mazgaj M, Wawrzycka-Adamczyk K, Szczeklik W, Musiał J, Sanak M. Circulating mitochondrial DNA in serum of patients with granulomatosis with polyangiitis. Clin Exp Immunol 2015;181(01):150-155

148 Wang H, Sha LL, Ma TT, Zhang LX, Chen M, Zhao MH. Circulating level of neutrophil extracellular traps is not a useful biomarker for assessing disease activity in antineutrophil cytoplasmic antibody-associated vasculitis. PLoS One 2016;11(02):e0148197

149 Grayson PC, Carmona-Rivera C, Xu L, et al; Rituximab in ANCAAssociated Vasculitis-Immune Tolerance Network Research Group. Neutrophil-related gene expression and low-density granulocytes associated with disease activity and response to treatment in antineutrophil cytoplasmic antibody-associated vasculitis. Arthritis Rheumatol 2015;67(07):1922-1932

150 Roth AJ, Ooi JD, Hess JJ, et al. Epitope specificity determines pathogenicity and detectability in ANCA-associated vasculitis. J Clin Invest 2013;123(04):1773-1783
151 Ohlsson SM, Ohlsson S, Söderberg D, et al. Neutrophils from vasculitis patients exhibit an increased propensity for activation by anti-neutrophil cytoplasmic antibodies. Clin Exp Immunol 2014;176(03):363-372

152 Ciavatta DJ, Yang J, Preston GA, et al. Epigenetic basis for aberrant upregulation of autoantigen genes in humans with ANCA vasculitis. J Clin Invest 2010;120(09):3209-3219

153 Leffler J, Stojanovich L, Shoenfeld Y, Bogdanovic G, Hesselstrand $\mathrm{R}$, Blom AM. Degradation of neutrophil extracellular traps is decreased in patients with antiphospholipid syndrome. Clin Exp Rheumatol 2014;32(01):66-70

154 Yalavarthi S, Gould TJ, Rao AN, et al. Release of neutrophil extracellular traps by neutrophils stimulated with antiphospholipid antibodies: a newly identified mechanism of thrombosis in the antiphospholipid syndrome. Arthritis Rheumatol 2015;67 (11):2990-3003

155 Meng H, Yalavarthi S, Kanthi Y, et al. In vivo role of neutrophil extracellular traps in antiphospholipid antibody-mediated venous thrombosis. Arthritis Rheumatol 2017;69(03):655-667

156 Gupta A, Hasler P, Gebhardt S, Holzgreve W, Hahn S. Occurrence of neutrophil extracellular DNA traps (NETs) in pre-eclampsia: a link with elevated levels of cell-free DNA? Ann N Y Acad Sci 2006; 1075:118-122

157 Gupta AK, Hasler P, Holzgreve W, Hahn S. Neutrophil NETs: a novel contributor to preeclampsia-associated placental hypoxia? Semin Immunopathol 2007;29(02):163-167

158 Marder W, Knight JS, Kaplan MJ, et al. Placental histology and neutrophil extracellular traps in lupus and pre-eclampsia pregnancies. Lupus Sci Med 2016;3(01):e000134

159 Skrzeczynska-Moncznik J, Wlodarczyk A, Zabieglo K, et al. Secretory leukocyte proteinase inhibitor-competent DNA deposits are potent stimulators of plasmacytoid dendritic cells: implication for psoriasis. J Immunol 2012;189(04):1611-1617

$160 \mathrm{Hu}$ SC, Yu HS, Yen FL, Lin CL, Chen GS, Lan CC. Neutrophil extracellular trap formation is increased in psoriasis and induces human $\beta$-defensin-2 production in epidermal keratinocytes. Sci Rep 2016;6:31119

161 Dwyer M, Shan Q D'Ortona S, et al. Cystic fibrosis sputum DNA has NETosis characteristics and neutrophil extracellular trap release is regulated by macrophage migration-inhibitory factor. J Innate Immun 2014;6(06):765-779

162 Marcos V, Zhou-Suckow Z, Önder Yildirim A, et al. Free DNA in cystic fibrosis airway fluids correlates with airflow obstruction. Mediators Inflamm 2015;2015:408935

163 Schauer C, Janko C, Munoz LE, et al. Aggregated neutrophil extracellular traps limit inflammation by degrading cytokines and chemokines. Nat Med 2014;20(05):511-517

164 Schett G, Schauer C, Hoffmann M, Herrmann M. Why does the gout attack stop? A roadmap for the immune pathogenesis of gout. RMD Open 2015;1(01, Suppl 1):e000046

165 Bennike TB, Carlsen TG, Ellingsen T, et al. Neutrophil extracellular traps in ulcerative colitis: a proteome analysis of intestinal biopsies. Inflamm Bowel Dis 2015;21(09):2052-2067

$166 \mathrm{He}$ Z, Si Y, Jiang T, et al. Phosphotidylserine exposure and neutrophil extracellular traps enhance procoagulant activity in patients with inflammatory bowel disease. Thromb Haemost 2016;115(04):738-751

167 Saffarzadeh M, Juenemann C, Queisser MA, et al. Neutrophil extracellular traps directly induce epithelial and endothelial cell death: a predominant role of histones. PLoS One 2012;7(02):e32366

168 Cheng OZ, Palaniyar N. NET balancing: a problem in inflammatory lung diseases. Front Immunol 2013;4:1

169 Rahman S, Gadjeva M. Does NETosis contribute to the bacterial pathoadaptation in cystic fibrosis? Front Immunol 2014;5:378

170 Yoo DG, Floyd M, Winn M, Moskowitz SM, Rada B. NET formation induced by Pseudomonas aeruginosa cystic fibrosis isolates measured as release of myeloperoxidase-DNA and neutrophil elastaseDNA complexes. Immunol Lett 2014;160(02):186-194 
171 Skopelja S, Hamilton BJ, Jones JD, et al. The role for neutrophil extracellular traps in cystic fibrosis autoimmunity. JCI Insight 2016;1(17):e88912

172 Ungurs MJ, Sinden NJ, Stockley RA. Progranulin is a substrate for neutrophil-elastase and proteinase- 3 in the airway and its concentration correlates with mediators of airway inflammation in COPD. Am J Physiol Lung Cell Mol Physiol 2014;306(01): L80-L87

173 Obermayer A, Stoiber W, Krautgartner WD, et al. New aspects on the structure of neutrophil extracellular traps from chronic obstructive pulmonary disease and in vitro generation. PLoS One 2014;9(05):e97784

174 Pedersen F, Marwitz S, Holz O, et al. Neutrophil extracellular trap formation and extracellular DNA in sputum of stable COPD patients. Respir Med 2015;109(10):1360-1362

175 Wright TK, Gibson PG, Simpson JL, McDonald VM, Wood LG, Baines KJ. Neutrophil extracellular traps are associated with inflammation in chronic airway disease. Respirology 2016;21 (03):467-475

176 Grabcanovic-Musija F, Obermayer A, Stoiber W, et al. Neutrophil extracellular trap (NET) formation characterises stable and exacerbated COPD and correlates with airflow limitation. Respir Res 2015;16:59

177 Dicker AJ, Crichton ML, Pumphrey EG, et al. Neutrophil extracellular traps are associated with disease severity and microbiota diversity in patients with chronic obstructive pulmonary disease. J Allergy Clin Immunol 2017 May 13. pii: S0091-6749(17) 30746-7.

178 Haldar P, Pavord ID. Noneosinophilic asthma: a distinct clinical and pathologic phenotype. J Allergy Clin Immunol 2007;119 (05):1043-1052, quiz 1053-1054

179 Choi Y, Pham LD, Lee DH, et al. Neutrophil extracellular DNA traps induce autoantigen production by airway epithelial cells. Mediators Inflamm 2017;2017:5675029

180 Dworski R, Simon HU, Hoskins A, Yousefi S. Eosinophil and neutrophil extracellular DNA traps in human allergic asthmatic airways. J Allergy Clin Immunol 2011;127(05):1260-1266

181 Yousefi S, Gold JA, Andina N, et al. Catapult-like release of mitochondrial DNA by eosinophils contributes to antibacterial defense. Nat Med 2008;14(09):949-953

182 Cunha AA, Porto BN, Nuñez NK, et al. Extracellular DNA traps in bronchoalveolar fluid from a murine eosinophilic pulmonary response. Allergy 2014;69(12):1696-1700

183 da Cunha AA, Nuñez NK, de Souza RG, et al. Recombinant human deoxyribonuclease attenuates oxidative stress in a model of eosinophilic pulmonary response in mice. Mol Cell Biochem 2016;413(1-2):47-55

184 Thomas GM, Carbo C, Curtis BR, et al. Extracellular DNA traps are associated with the pathogenesis of TRALI in humans and mice. Blood 2012;119(26):6335-6343

185 Caudrillier A, Kessenbrock K, Gilliss BM, et al. Platelets induce neutrophil extracellular traps in transfusion-related acute lung injury. J Clin Invest 2012;122(07):2661-2671

186 Semeraro F, Ammollo CT, Morrissey JH, et al. Extracellular histones promote thrombin generation through platelet-dependent mechanisms: involvement of platelet TLR2 and TLR4. Blood 2011;118(07):1952-1961

187 Galdiero MR, Garlanda C, Jaillon S, Marone G, Mantovani A. Tumor associated macrophages and neutrophils in tumor progression. J Cell Physiol 2013;228(07):1404-1412

188 Berger-Achituv S, Brinkmann V, Abed UA, et al. A proposed role for neutrophil extracellular traps in cancer immunoediting. Front Immunol 2013;4:48

189 Houghton AM, Rzymkiewicz DM, Ji H, et al. Neutrophil elastasemediated degradation of IRS- 1 accelerates lung tumor growth. Nat Med 2010;16(02):219-223

190 Sangaletti S, Tripodo C, Vitali C, et al. Defective stromal remodeling and neutrophil extracellular traps in lymphoid tissues favor the transition from autoimmunity to lymphoma. Cancer Discov 2014;4(01):110-129

191 Gaida MM, Steffen TG, Günther F, et al. Polymorphonuclear neutrophils promote dyshesion of tumor cells and elastasemediated degradation of E-cadherin in pancreatic tumors. Eur J Immunol 2012;42(12):3369-3380

192 Kolaczkowska E, Jenne CN, Surewaard BG, et al. Molecular mechanisms of NET formation and degradation revealed by intravital imaging in the liver vasculature. Nat Commun 2015; 6:6673

193 An H, Zhu Y, Xie H, et al. Increased expression of interleukin-8 is an independent indicator of poor prognosis in clear-cell renal cell carcinoma. Tumour Biol 2016;37(04):4523-4529

194 Wang J, Wang Y, Wang S, et al. Bone marrow-derived mesenchymal stem cell-secreted IL-8 promotes the angiogenesis and growth of colorectal cancer. Oncotarget 2015;6(40):42825-42837

195 Demers M, Wong SL, Martinod K, et al. Priming of neutrophils toward NETosis promotes tumor growth. Oncolmmunology 2016;5(05):e1134073

196 Zhao JJ, Pan K, Wang W, et al. The prognostic value of tumorinfiltrating neutrophils in gastric adenocarcinoma after resection. PLoS One 2012;7(03):e33655

197 Perisanidis C, Kornek G, Pöschl PW, et al. High neutrophil-tolymphocyte ratio is an independent marker of poor diseasespecific survival in patients with oral cancer. Med Oncol 2013;30 (01):334

198 Xiao WK, Chen D, Li SQ, Fu SJ, Peng BG, Liang LJ. Prognostic significance of neutrophil-lymphocyte ratio in hepatocellular carcinoma: a meta-analysis. BMC Cancer 2014;14:117

199 Bald T, Quast T, Landsberg J, et al. Ultraviolet-radiation-induced inflammation promotes angiotropism and metastasis in melanoma. Nature 2014;507(7490):109-113

200 Alfaro C, Teijeira A, Oñate C, et al. Tumor-produced interleukin-8 attracts human myeloid-derived suppressor cells and elicits extrusion of neutrophil extracellular traps (NETs). Clin Cancer Res 2016;22(15):3924-3936

201 Baj-Krzyworzeka M, Baran J, Weglarczyk K, et al. Tumour-derived microvesicles (TMV) mimic the effect of tumour cells on monocyte subpopulations. Anticancer Res 2010;30(09):3515-3519

202 Terraube V, Marx I, Denis CV. Role of von Willebrand factor in tumor metastasis. Thromb Res 2007;120(Suppl 2):S64-S70

203 Erpenbeck L, Nieswandt B, Schön M, Pozgajova M, Schön MP. Inhibition of platelet GPIb alpha and promotion of melanoma metastasis. J Invest Dermatol 2010;130(02):576-586

204 Bauer AT, Suckau J, Frank K, et al. von Willebrand factor fibers promote cancer-associated platelet aggregation in malignant melanoma of mice and humans. Blood 2015;125(20):3153-3163

205 Guglietta S, Chiavelli A, Zagato E, et al. Coagulation induced by C3aR-dependent NETosis drives protumorigenic neutrophils during small intestinal tumorigenesis. Nat Commun 2016;7:11037

206 Spicer JD, McDonald B, Cools-Lartigue JJ, et al. Neutrophils promote liver metastasis via Mac-1-mediated interactions with circulating tumor cells. Cancer Res 2012;72(16):3919-3927

207 Labelle M, Begum S, Hynes RO. Platelets guide the formation of early metastatic niches. Proc Natl Acad Sci U S A 2014;111(30): E3053-E3061

208 Huh SJ, Liang S, Sharma A, Dong C, Robertson GP. Transiently entrapped circulating tumor cells interact with neutrophils to facilitate lung metastasis development. Cancer Res 2010;70(14): 6071-6082

209 Ramirez GA, Manfredi AA, Rovere-Querini P, Maugeri N. Bet on NETs! Or on how to translate basic science into clinical practice. Front Immunol 2016;7:417

210 Nauseef WM, Kubes P. Pondering neutrophil extracellular traps with healthy skepticism. Cell Microbiol 2016;18(10):1349-1357

211 Patel S, Kumar S, Jyoti A, et al. Nitric oxide donors release extracellular traps from human neutrophils by augmenting free radical generation. Nitric Oxide 2010;22(03):226-234 
212 Garcia RJ, Francis L, Dawood M, Lai ZW, Faraone SV, Perl A. Attention deficit and hyperactivity disorder scores are elevated and respond to $\mathrm{N}$-acetylcysteine treatment in patients with systemic lupus erythematosus. Arthritis Rheum 2013;65(05):1313-1318

213 Lai ZW, Hanczko R, Bonilla E, et al. N-acetylcysteine reduces disease activity by blocking mammalian target of rapamycin in $\mathrm{T}$ cells from systemic lupus erythematosus patients: a randomized, double-blind, placebo-controlled trial. Arthritis Rheum 2012;64(09):2937-2946

214 Wahono CS, Rusmini H, Soelistyoningsih D, et al. Effects of 1,25 $(\mathrm{OH}) 2 \mathrm{D} 3$ in immune response regulation of systemic lupus erithematosus (SLE) patient with hypovitamin D. Int J Clin Exp Med 2014;7(01):22-31

215 Smith CK, Vivekanandan-Giri A, Tang C, et al. Neutrophil extracellular trap-derived enzymes oxidize high-density lipoprotein: an additional proatherogenic mechanism in systemic lupus erythematosus. Arthritis Rheumatol 2014;66(09):2532-2544

216 Cohen SB, Emery P, Greenwald MW, et al; REFLEX Trial Group. Rituximab for rheumatoid arthritis refractory to anti-tumor necrosis factor therapy: Results of a multicenter, randomized, double-blind, placebo-controlled, phase III trial evaluating primary efficacy and safety at twenty-four weeks. Arthritis Rheum 2006;54(09):2793-2806

217 Stone JH, Merkel PA, Spiera R, et al; RAVE-ITN Research Group. Rituximab versus cyclophosphamide for ANCA-associated vasculitis. N Engl J Med 2010;363(03):221-232

218 Schreiber A, Otto B, Ju X, et al. Membrane proteinase 3 expression in patients with Wegener's granulomatosis and in human hematopoietic stem cell-derived neutrophils. J Am Soc Nephrol 2005; 16(07):2216-2224

219 Huang YM, Wang H, Wang C, Chen M, Zhao MH. Promotion of hypercoagulability in antineutrophil cytoplasmic antibodyassociated vasculitis by C5a-induced tissue factor-expressing microparticles and neutrophil extracellular traps. Arthritis Rheumatol 2015;67(10):2780-2790

220 Sciascia S, Radin M, Yazdany J, et al. Expanding the therapeutic options for renal involvement in lupus: eculizumab, available evidence. Rheumatol Int 2017;37(08):1249-1255

221 Barnado A, Crofford LJ, Oates JC. At the bedside: neutrophil extracellular traps (NETs) as targets for biomarkers and therapies in autoimmune diseases. J Leukoc Biol 2016;99(02): 265-278

222 Knight JS, Zhao W, Luo W, et al. Peptidylarginine deiminase inhibition is immunomodulatory and vasculoprotective in murine lupus. J Clin Invest 2013;123(07):2981-2993

223 Knight JS, Subramanian V, O'Dell AA, et al. Peptidylarginine deiminase inhibition disrupts NET formation and protects against kidney, skin and vascular disease in lupus-prone MRL/ lpr mice. Ann Rheum Dis 2015;74(12):2199-2206

224 Willis VC, Gizinski AM, Banda NK, et al. N- $\alpha$-benzoyl-N5-(2chloro-1-iminoethyl)-L-ornithine amide, a protein arginine deiminase inhibitor, reduces the severity of murine collagen-induced arthritis. J Immunol 2011;186(07):4396-4404

225 Ham A, Rabadi M, Kim M, et al. Peptidyl arginine deiminase-4 activation exacerbates kidney ischemia-reperfusion injury. Am J Physiol Renal Physiol 2014;307(09):F1052-F1062
226 Marin-Esteban V, Turbica I, Dufour G, et al. Afa/Dr diffusely adhering Escherichia coli strain C1845 induces neutrophil extracellular traps that kill bacteria and damage human enterocytelike cells. Infect Immun 2012;80(05):1891-1899

227 Pieterse E, Rother N, Yanginlar C, Hilbrands LB, van der Vlag J. Neutrophils discriminate between lipopolysaccharides of different bacterial sources and selectively release neutrophil extracellular traps. Front Immunol 2016;7:484

228 Gillenius E, Urban CF. The adhesive protein invasin of Yersinia pseudotuberculosis induces neutrophil extracellular traps via $\beta 1$ integrins. Microbes Infect 2015;17(05):327-336

229 Byrd AS, O’Brien XM, Johnson CM, Lavigne LM, Reichner JS. An extracellular matrix-based mechanism of rapid neutrophil extracellular trap formation in response to Candida albicans. J Immunol 2013;190(08):4136-4148

230 Waisberg M, Molina-Cruz A, Mizurini DM, et al. Plasmodium falciparum infection induces expression of a mosquito salivary protein (Agaphelin) that targets neutrophil function and inhibits thrombosis without impairing hemostasis. PLoS Pathog 2014;10 (09):e1004338

231 Shimony A, Zahger D, Gilutz H, et al. Cell free DNA detected by a novel method in acute ST-elevation myocardial infarction patients. Acute Card Care 2010;12(03):109-111

232 Cui M, Fan M, Jing R, et al. Cell-Free circulating DNA: a new biomarker for the acute coronary syndrome. Cardiology 2013; 124(02):76-84

233 Helseth R, Solheim S, Arnesen H, Seljeflot I, Opstad TB. The time course of markers of neutrophil extracellular traps in patients undergoing revascularisation for acute myocardial infarction or stable angina pectoris. Mediators Inflamm 2016;2016:2182358

234 Rainer TH, Wong LK, Lam W, et al. Prognostic use of circulating plasma nucleic acid concentrations in patients with acute stroke. Clin Chem 2003;49(04):562-569

235 Geiger S, Holdenrieder S, Stieber P, et al. Nucleosomes in serum of patients with early cerebral stroke. Cerebrovasc Dis 2006;21 (1-2):32-37

236 Lam NY, Rainer TH, Wong LK, Lam W, Lo YM. Plasma DNA as a prognostic marker for stroke patients with negative neuroimaging within the first $24 \mathrm{~h}$ of symptom onset. Resuscitation 2006; 68(01):71-78

237 Geiger S, Holdenrieder S, Stieber P, et al. Nucleosomes as a new prognostic marker in early cerebral stroke. J Neurol 2007;254 (05):617-623

238 Tsai NW, Lin TK, Chen SD, et al. The value of serial plasma nuclear and mitochondrial DNA levels in patients with acute ischemic stroke. Clin Chim Acta 2011;412(5-6):476-479

239 Hirose T, Hamaguchi S, Matsumoto N, et al. Presence of neutrophil extracellular traps and citrullinated histone $\mathrm{H} 3$ in the bloodstream of critically ill patients. PLoS One 2014;9(11): e111755

240 Thålin C, Demers M, Blomgren B, et al. NETosis promotes cancerassociated arterial microthrombosis presenting as ischemic stroke with troponin elevation. Thromb Res 2016;139:56-64

241 Laridan E, Denorme F, Desender L, et al. Neutrophil extracellular traps in ischemic stroke thrombi. Ann Neurol 2017;82(02): 223-232 